ARTICLE

\title{
Graphitic phosphorus coordinated single Fe atoms for hydrogenative transformations
}

\author{
Xiangdong Long ${ }^{1,2}$, Zelong $\mathrm{Li}^{3}$, Guang Gao ${ }^{1}$, Peng Sun ${ }^{1}$, Jia Wang ${ }^{1}$, Bingsen Zhang ${ }^{4}{ }^{4}$, Jun Zhong ${ }^{5}$, \\ Zheng Jiang (iD ${ }^{6}$ \& Fuwei Li (iD ${ }^{1,7 凶}$
}

Single-atom metal-nitrogen-carbon $(\mathrm{M}-\mathrm{N}-\mathrm{C})$ catalysts have sparked intensive interests, however, the development of an atomically dispersed metal-phosphorus-carbon (M-P-C) catalyst has not been achieved, although molecular metal-phosphine complexes have found tremendous applications in homogeneous catalysis. Herein, we successfully construct graphitic phosphorus species coordinated single-atom Fe on P-doped carbon, which display outstanding catalytic performance and reaction generality in the heterogeneous hydrogenation of $\mathrm{N}$-heterocycles, functionalized nitroarenes, and reductive amination reactions, while the corresponding atomically dispersed Fe atoms embedded on $\mathrm{N}$-doped carbon are almost inactive under the same reaction conditions. Furthermore, we find that the catalytic activity of graphitic phosphorus coordinated single-atom Fe sharply decreased when $\mathrm{Fe}$ atoms were transformed to Fe clusters/nanoparticles by post-impregnation Fe species. This work can be of fundamental interest for the design of single-atom catalysts by utilizing $\mathrm{P}$ atoms as coordination sites as well as of practical use for the application of M-P-C catalysts in heterogeneous catalysis.

\footnotetext{
${ }^{1}$ State Key Laboratory for Oxo Synthesis and Selective Oxidation, Suzhou Research Institute of LICP, Lanzhou Institute of Chemical Physics (LICP), Chinese Academy of Sciences, 730000 Lanzhou, China. ${ }^{2}$ University of Chinese Academy of Sciences, 100049 Beijing, China. ${ }^{3}$ Advanced Catalysis Center, College of Chemistry and Chemical Engineering, Lanzhou University, 730000 Lanzhou, China. ${ }^{4}$ Shenyang National Laboratory for Materials Science (SYNL), Institute of Metal Research, Chinese Academy of Sciences, 110016 Shenyang, China. ${ }^{5}$ Jiangsu Key Laboratory for Carbon-Based Functional Materials \& Devices, Institute of Functional Nano \& Soft Materials (FUNSOM), Soochow University, 215123 Suzhou, China. ${ }^{6}$ Shanghai Synchrotron Radiation Facility, Zhangjiang Lab, Shanghai Advanced Research Institute, Chinese Academy of Science, 201210 Shanghai, China. ${ }^{7}$ Dalian National Laboratory for Clean Energy, 116023 Dalian, China. ${ }^{凶}$ email: fuweili@licp.cas.cn
} 
$\mathrm{T}$ he coordination environment could deeply influence the catalytic performance of metal species through metal -support interactions (MSIs) ${ }^{1,2}$, especially when the scale of metal species downsizes to single atom, that is, the single-atom catalysts $(\mathrm{SACs})^{3-5}$, wherein the metal atoms are located individually on support and are stabilized by neighboring surface atoms through covalent coordination or ionic interactions, and the coordination atoms could drastically tune the electronic and geometric structure of the supported single metal atoms $s^{6,7}$. Hence, modifying the surface atoms of support to construct an appropriate coordination environment for metal atoms is one of the most promising strategies to synthesize highly efficient and stable SACs ${ }^{8,9}$. Conventionally, the voids or vacancy defects on metal oxides (e.g., $\mathrm{TiO}_{2}, \mathrm{CeO}_{2}, \mathrm{ZrO}_{2}$ ) or zeolites are commonly used as coordination sites for single metal atoms ${ }^{10-12}$.

Over the past decades, the well-structured and crystallized nanocarbon-based materials have been widely used in catalysis, due to their unique electronic and structural properties as well as outstanding stability under hash reaction conditions ${ }^{13}$. Particularly, the carbon matrix could be easily modified via heteroatoms doping to introduce heteroatom-containing defects, which are ideal coordination sites for single metal atoms ${ }^{14,15}$. Within this context, metal-nitrogen-carbon catalyst $(\mathrm{M}-\mathrm{N}-\mathrm{C}, \mathrm{M}$ refers to nonprecious $\mathrm{Fe}, \mathrm{Co}$, Ni etc.), using $\mathrm{N}$ to anchor metal atoms, have recently attracted tremendous attention as a representative bridging the homogeneous and heterogeneous catalysis ${ }^{5}$, and the coordinated $\mathrm{M}-\mathrm{N}_{x}$ centers have displayed excellent activities in a vast array of thermal and electrocatalysis ${ }^{16-19}$. However, singleatom metal-phosphorus-carbon $(\mathrm{M}-\mathrm{P}-\mathrm{C})$ catalyst with $\mathrm{P}$ atoms as the coordination sites has not been successfully established, which is principally due to the $\mathrm{P}$ atom having distinct physicochemical properties with $\mathrm{N}$ atom, such as larger atom radius and lower electronegativity, then doping the $\mathrm{P}$ atom into the carbon skeleton prefers to form a distorted configuration ${ }^{20}$, and the $\mathrm{P}$ species are easily oxidized to electron-deficient $\mathrm{PO}_{x}$ species, which will retard the formation of P-containing sites or defects to act as optimal electronic and geometric coordination environment for single metal atoms. In fact, $\mathrm{P}$ atom is widely used as the coordination center for metal in organometallic complexes $^{21}$, and it is well known that the molecular metal (particularly transition metal) phosphine complexes have found wide applications in homogeneous catalytic transformations, such as hydrogenation $s^{22}$, coupling reactions ${ }^{23,24}$, carbonylation ${ }^{25,26}$, etc. Therefore, the development of single-atom $\mathrm{M}-\mathrm{P}-\mathrm{C}$ catalysts is in great demand for broadening SACs and exploring their sustainable catalysis.

Selective hydrogenative transformation of multifunctional substrates to valuable chemicals is a long-standing issue in catalysis. A prerequisite for achieving desired products with high selectivity is rationally designing the catalyst $\mathrm{t}^{27}$. In this work, we report the fabrication of surface graphitic phosphorus species $\left(\mathrm{P}_{\text {grap }}\right)$-coordinated Fe SAC (Fe- $\mathrm{P}_{900}$-PCC) through templatedsacrificial approach using phytic acid and it contained $\mathrm{Fe}$ species as $\mathrm{P}$ and Fe precursors. It was revealed by integrated spectroscopy characterization and theoretical calculations that the Fe single atom is coordinated by four $\mathrm{P}$ atoms and one dioxygen molecule, adopting a pyramidal structure of $\mathrm{O}_{2}-\mathrm{Fe}-\mathrm{P}_{4}$. After the dioxygen was removed by hydrogen under the reaction conditions, the insitu-generated $\mathrm{Fe}-\mathrm{P}_{4}$ sites displayed high selectivity and outstanding stability for hydrogenations of different unsaturated functions (nitroarenes and N-heterocycles), and the reductive amination reactions as well. On the contrary, the planar $\mathrm{Fe}-\mathrm{N}_{4}$ active site in the corresponding $\mathrm{Fe}-\mathrm{N}-\mathrm{C}$ catalyst was inactive for these hydrogenative transformations under the same reaction conditions, suggesting that the coordinated $\mathrm{P}$ atoms play a crucial role for the catalytic performance of Fe single atom.

\section{Results and discussion}

Catalyst synthesis and characterization. P-doped carbon catalysts are fabricated using a templated-sacrificial approach ${ }^{28}$. The typical synthesis process is illustrated in Fig. 1a. Briefly, the precursors (sucrose and phytic acid) and hard template (silica colloid, $14 \mathrm{~nm} \mathrm{SiO}{ }_{2}$ nanoparticles dispersed in water) were mixed to form a homogeneous mixture and then carbonized at temperature between 700 and $1100{ }^{\circ} \mathrm{C}$. Afterwards, the hard template was removed by hydrofluoric acid $(10 \mathrm{wt} \%)$ to obtain porous carbon catalysts (PCCs). For comparison, non-heteroatom-doped PCC and N-doped PCC were also prepared in a similar procedure except that no phytic acid was added or phytic acid was replaced by cyanamide ( $\mathrm{N}$ precursor), respectively. It is worth noting that the Fe element is ubiquitous in the earth's crust (the second most abundant metal); most commercial compounds or materials naturally contain low content of Fe impurities ${ }^{29,30}$. Directly utilizing raw materials containing metal as active components in the catalysts would be a quite meaningful strategy for the synthesis of catalysts $^{31,32}$. Herein, we found that the Fe species originating from initial raw materials could be successfully inherited by the as-prepared carbon catalysts; no other external Fe salts are needed (the contents of Fe in raw materials are listed in Supplementary Table 1). The synthesized non-heteroatom-doped, N-doped and $\mathrm{P}$-doped PCC are denoted as $\mathrm{Fe}-\mathrm{C}_{x}-\mathrm{PCC}, \mathrm{Fe}-\mathrm{N}_{x^{-}} \mathrm{PCC}$ and $\mathrm{Fe}-\mathrm{P}_{x^{-}}$ PCC, respectively ( $x$ stands for the carbonization temperature in degree Celsius). The inductively coupled plasma mass spectroscopy (ICP-MS) analysis reveals Fe loading of $0.0016,0.0023$ and $0.071 \mathrm{wt} \%$ for $\mathrm{Fe}-\mathrm{C}_{900}-\mathrm{PCC}, \mathrm{Fe}-\mathrm{N}_{900}-\mathrm{PCC}$ and $\mathrm{Fe}-\mathrm{P}_{900}-\mathrm{PCC}$, respectively (Supplementary Table 2).

X-ray photoelectron spectroscopy (XPS) survey scans show that the heteroatoms $(\mathrm{N}$ or $\mathrm{P})$ were doped into the porous carbon successfully (Supplementary Fig. 1). The elemental compositions of $\mathrm{Fe}-\mathrm{C}_{900}-\mathrm{PCC}, \mathrm{Fe}-\mathrm{N}_{900}-\mathrm{PCC}$ and $\mathrm{Fe}-\mathrm{P}_{900}-\mathrm{PCC}$ are listed in Supplementary Table 3. The results of $\mathrm{N}_{2}$ adsorption-desorption curves indicate that the synthesized catalysts possess an obvious mesoporous structure (Supplementary Fig. 2) and high specific Brunauer-Emmett-Teller (BET) surface area: $\mathrm{Fe}^{-\mathrm{C}_{900}} \mathrm{PCC}$ $\left(768 \mathrm{~m}^{2} \mathrm{~g}^{-1}\right), \mathrm{Fe}-\mathrm{N}_{900}-\mathrm{PCC}\left(628 \mathrm{~m}^{2} \mathrm{~g}^{-1}\right)$ and $\mathrm{Fe}-\mathrm{P}_{900}$-PCC $(511$ $\left.\mathrm{m}^{2} \mathrm{~g}^{-1}\right)$; structural properties of catalysts are listed in Supplementary Table 4 . The high surface area and large pore volume are beneficial to the dispersion of active sites and the mass transfer of reactants. X-ray diffraction (XRD) patterns of catalysts are characterized by the low intensity of the broad peaks at $2 \theta=23$ and $43^{\circ}$ (Supplementary Fig. 3), which are ascribed to the fingerprints of graphite (002) and (100) (ICSD No. 617290) reflections ${ }^{33}$. Moreover, no diffraction peaks corresponding to crystalline species of $\mathrm{Fe}$ are observed. Their Raman spectra (Supplementary Fig. 4) are dominated by two major peaks at $1338 \mathrm{~cm}^{-1}$ (D-band) and $1589 \mathrm{~cm}^{-1}$ (G-band) corresponding to the disordered and graphitic $\mathrm{sp}^{2}$ carbon, respectively ${ }^{34}$. The transmission electron microscopy (TEM) images show that Fe$\mathrm{C}_{900}$-PCC, $\mathrm{Fe}-\mathrm{N}_{900}-\mathrm{PCC}$ and $\mathrm{Fe}-\mathrm{P}_{900}$-PCC have a sponge-like three-dimensional network structure (Fig. $1 \mathrm{~b}$ and Supplementary Fig. 5). High-resolution TEM (HRTEM) images reveal that the bulk of catalysts is amorphous carbon, but the surface is surrounded by graphitic layers (4-7 layers, Fig. 1c and Supplementary Fig. 6). The existence of $\mathrm{Fe}$ in $\mathrm{Fe}-\mathrm{N}_{900}-\mathrm{PCC}$ and $\mathrm{Fe}-\mathrm{P}_{900}$-PCC was further confirmed by means of aberrationcorrected scanning transmission electron microscopy (ACSTEM). As shown in Fig. 1d, Supplementary Figs. 7 and 8, single Fe atoms are dispersed on these catalysts. Additionally, some of the carbon-shells-encapsulated Fe nanoparticles are also observed in these carbon materials (Supplementary Figs. 9 and 10), but no $\mathrm{Fe}-\mathrm{Fe}$ coordination has been detected in the characterization of Fe K-edge extended X-ray absorption fine structure (EXAFS, which will be discussed below), suggesting the majority of $\mathrm{Fe}$ 


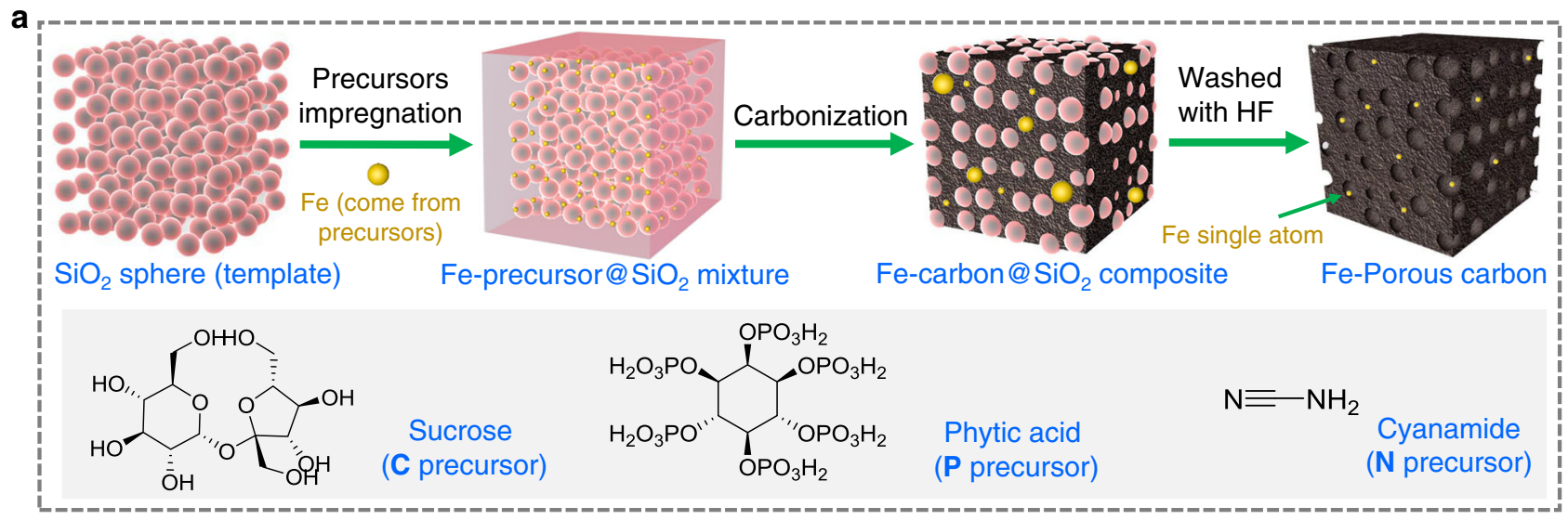

b

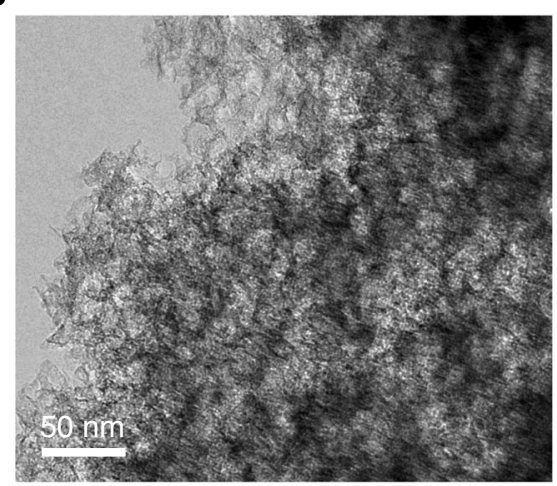

c

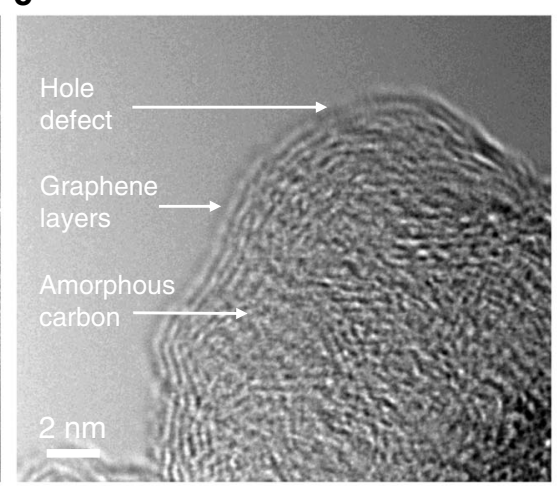

d

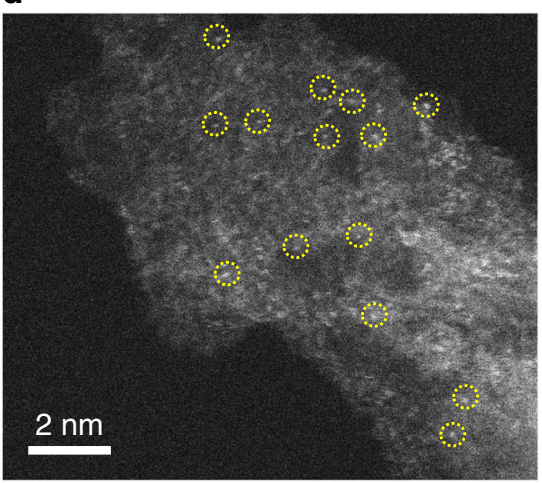

e

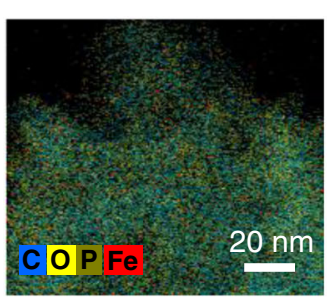

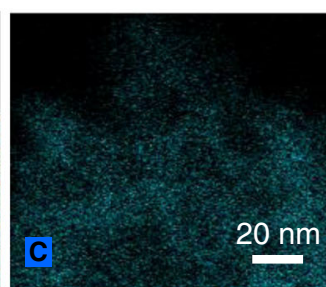
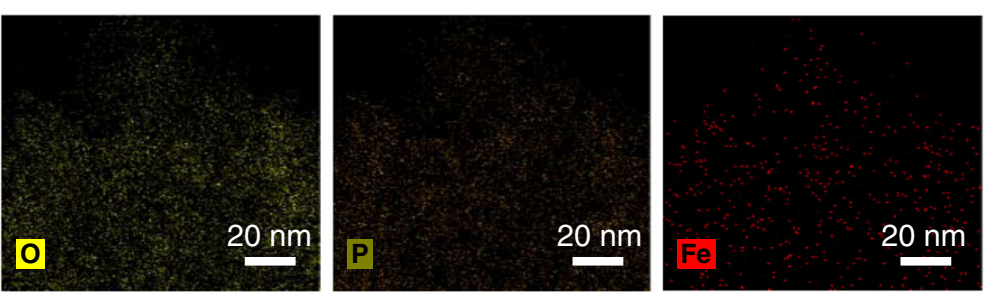

Fig. 1 Structure characterizations of Fe-P/900-PCC. a Schematic illustration of the preparation process of PCCs. b TEM image. $\mathbf{c}$ HRTEM image. $\mathbf{d}$ ACSTEM image, Fe single atoms are highlighted by yellow circles. e EDS mapping images for various elements.

species exist in the form of single atom, and the proportion of carbon-shells-encapsulated Fe aggregates is extremely low. For $\mathrm{Fe}-\mathrm{P}_{900}-\mathrm{PCC}$, the energy-dispersive spectroscopy (EDS) mappings indicate that $\mathrm{Fe}, \mathrm{O}$ and $\mathrm{P}$ are uniformly distributed on $\mathrm{Fe}-$ $\mathrm{P}_{900}$-PCC (Fig. 1e).

Catalytic performance. Selective hydrogenation of unsaturated $\mathrm{N}$-heterocycles plays an important role in the generation of aliphatic derivatives, which are crucial starting materials in the synthesis of pharmaceuticals, dyes and fine chemicals ${ }^{35}$. Here, the hydrogenation of quinoline is chosen as a model reaction to evaluate the catalytic performance of synthesized catalysts. As shown in Table 1, no quinoline is converted in the absence of catalyst (entry 1). The hydrogenation also does not occur over Fe$\mathrm{C}_{900}$-PCC catalyst (entry 2), even though the reaction temperature is raised to $200^{\circ} \mathrm{C}$ (entry 3). Besides, $\mathrm{Fe}-\mathrm{N}_{900}-\mathrm{PCC}$ is also inactive at $150^{\circ} \mathrm{C}$ (entry 4), but a $7 \%$ yield of tetrahydroquinoline has been achieved at $200^{\circ} \mathrm{C}$ (entry 5). In the case of Fe- $\mathrm{P}_{900}$-PCC catalyst, the conversion of quinoline reaches $93 \%$ at $150{ }^{\circ} \mathrm{C}$ with $99 \%$ of tetrahydroquinoline selectivity (entry 6). All the quinoline could be transformed to tetrahydroquinoline with prolonging reaction time to $18 \mathrm{~h}$ (entry 7), and no other by-products are detected by gas chromatograph (GC) and gas chromatograph- mass spectrometer (GC-MS). The functional group tolerance survey of various unsaturated N-heterocycles was conducted with Fe-P ${ }_{900}$-PCC as the optimal catalyst (Supplementary Fig. 11). The substituent position of quinoline has no influence on the yield of the corresponding tetrahydroquinoline $(\mathbf{2} \mathbf{b}-\mathbf{d})$. Other functional groups, such as ester, hydroxyl, amino and benzo[h]quinoline, are also perfectly tolerated $(\mathbf{2 e}-\mathbf{h})$. In addition, the oxygencontaining heterocycles, benzofuran, can also be hydrogenated to 2,3-dihydrobenzofuran (2i) under this catalytic system with $99 \%$ yield.

Role of $\mathbf{N}$ and $\mathbf{P}$. The obvious differences of catalytic activity among $\mathrm{Fe}-\mathrm{C}_{900}-\mathrm{PCC}, \mathrm{Fe}-\mathrm{N}_{900}-\mathrm{PCC}$ and $\mathrm{Fe}-\mathrm{P}_{900}-\mathrm{PCC}$ provoke us to discriminate the role of $\mathrm{Fe}, \mathrm{N}$ and $\mathrm{P}$ in the $\mathrm{PCC}$ catalysts. Since the content of $\mathrm{Fe}$ in $\mathrm{Fe}-\mathrm{C}_{900}-\mathrm{PCC}$ and $\mathrm{Fe}-\mathrm{N}_{900}-\mathrm{PCC}$ is lower than that in Fe- $\mathrm{P}_{900}$-PCC (Supplementary Table 2), we first wondered if the different content of Fe led to different catalytic activity, we then deliberately added $130 \mathrm{mg} \mathrm{Fe}\left(\mathrm{NO}_{3}\right)_{3} \cdot 9 \mathrm{H}_{2} \mathrm{O}$ into the initial precursor mixture of $\mathrm{Fe}-\mathrm{C}_{900}-\mathrm{PCC}$ and $\mathrm{Fe}-\mathrm{N}_{900}-\mathrm{PCC}$ to obtain high content of Fe samples, which are denoted as Fe@Fe- $\mathrm{C}_{900^{-}}$ PCC and Fe@Fe- $\mathrm{N}_{900}$-PCC. The ICP-MS results indicate that the content of $\mathrm{Fe}$ in $\mathrm{Fe} @ \mathrm{Fe}-\mathrm{C}_{900}-\mathrm{PCC}(0.038 \mathrm{wt} \%)$ and $\mathrm{Fe} @ \mathrm{Fe}-\mathrm{N}_{900^{-}}$ PCC $(0.057 \mathrm{wt} \%)$ is much higher than the content of $\mathrm{Fe}$ in 
Table 1 Screening of catalysts for the hydrogenation of quinoline to tetrahydroquinoline.

\begin{tabular}{|c|c|c|c|c|}
\hline Entry & Catalyst & Temperature $\left({ }^{\circ} \mathrm{C}\right)$ & Conversion (\%) & Yield (\%) \\
\hline 1 & Blank & 150 & 0 & 0 \\
\hline 2 & $\mathrm{Fe}-\mathrm{C}_{900}-\mathrm{PCC}$ & 150 & 0 & 0 \\
\hline 5 & $\mathrm{Fe}-\mathrm{N}_{900}-\mathrm{PCC}$ & 200 & 8 & 7 \\
\hline 6 & $\mathrm{Fe}-\mathrm{P}_{900}-\mathrm{PCC}$ & 150 & 93 & 92 \\
\hline $7^{a}$ & $\mathrm{Fe}-\mathrm{P}_{900}-\mathrm{PCC}$ & 150 & 99 & 98 \\
\hline 8 & $\mathrm{Fe} @ \mathrm{Fe}-\mathrm{C}_{900}-\mathrm{PCC}$ & 150 & 0 & 0 \\
\hline 9 & $\mathrm{Fe} @ \mathrm{Fe}-\mathrm{N}_{900}-\mathrm{PCC}$ & 150 & 0 & 0 \\
\hline 10 & $\mathrm{P}_{900}$-PCC-polymer & 150 & 0 & 0 \\
\hline
\end{tabular}

$\mathrm{Fe}-\mathrm{C}_{900}-\mathrm{PCC}(0.0016 \mathrm{wt} \%)$ and $\mathrm{Fe}-\mathrm{N}_{900}$-PCC (0.0023 wt\%), and is close to $\mathrm{Fe}-\mathrm{P}_{900}-\mathrm{PCC}(0.071 \mathrm{wt} \%)$. AC-STEM and HRTEM images as well as Fe K-edge EXAFS spectrum reveal that both $\mathrm{Fe}$ single atoms and nanoparticles are dispersed on Fe@Fe- $\mathrm{C}_{900}$-PCC (Supplementary Fig. 12). However, this catalyst is inactive for hydrogenation of quinoline (Table 1 , entry 8), suggesting that solely $\mathrm{Fe}$-doped porous carbon without heteroatoms doping could not catalyze the hydrogenation reaction.

For Fe@Fe- $\mathrm{N}_{900}$-PCC, the characterizations of AC-STEM and EXAFS demonstrate that the Fe atoms are atomically dispersed on N-doped porous carbon (Supplementary Fig. 13), and the quantitative EXAFS curve fitting reveals that the single Fe atom adopts a planar $\mathrm{Fe}-\mathrm{N}_{4}$ structure (see Supplementary Fig. 14 and Supplementary Table 6 for details). Surprisingly, Fe@Fe- $\mathrm{N}_{900^{-}}$ PCC has no catalytic activity for hydrogenation (Table 1, entry 9), even though its Fe content is similar to the P-doped Fe- $\mathrm{P}_{900}-\mathrm{PCC}$. We then performed the density functional theory (DFT) calculations to investigate the catalytic behavior of $\mathrm{Fe}-\mathrm{N}_{4}$ sites toward $\mathrm{H}_{2}$ adsorption and activation; the results demonstrate that $\mathrm{H}_{2}$ can only physically adsorb on the $\mathrm{Fe}-\mathrm{N}_{4}$ site, and the resultant $\mathrm{H}-\mathrm{H}$ bond length $(0.75 \AA)$ is equal to the free $\mathrm{H}_{2}$ molecule (Supplementary Fig. 15), indicating that the $\mathrm{Fe}-\mathrm{N}_{4}$ sites are intrinsically inert to activate $\mathrm{H}_{2}$, which is consistent with the experimental results. In fact, the $\mathrm{Fe}-\mathrm{N}_{4}$ site was mostly reported in oxidation reactions ${ }^{16,19}$, electrochemical oxidation reduction reaction (ORR) ${ }^{36,37}$ or $\mathrm{CO}_{2}$ electroreduction reaction ${ }^{38,39}$, and $\mathrm{Fe}-\mathrm{N}-\mathrm{C}$ SACs for hydrogenation reaction is rarely reported.

Next, we investigated the reason why $\mathrm{Fe}_{-} \mathrm{P}_{900}$-PCC has high activity for hydrogenation reaction. Firstly, in order to explore whether the Fe-free P-doping carbon catalyst has the activity for hydrogenation $^{40,41}$, we particularly synthesized an ultrapure Pdoped carbon (denoted as $\mathrm{P}_{900}$-PCC-polymer) via pyrolysis of polytris(4-vinylphenyl)phosphane, which is synthesized according to Ding's reported procedure ${ }^{42}$, and its Fe-containing analog (denoted as $\mathrm{Fe}-\mathrm{P}_{900}-\mathrm{PCC}$-polymer) was also prepared as a reference catalyst through pyrolysis of Fe-coordinated polytris (4-vinylphenyl)phosphane. ICP-MS analysis reveals Fe loading of 0.000023 and 0.096 wt $\%$ for $\mathrm{P}_{900^{-}} \mathrm{PCC}$-polymer and $\mathrm{Fe}-\mathrm{P}_{900^{-}}$ PCC-polymer, respectively. Nevertheless, both $\mathrm{P}_{900}$-PCC-polymer and $\mathrm{Fe}-\mathrm{P}_{900}-\mathrm{PCC}$-polymer showed no activity in the quinoline hydrogenation (Table 1, entries 10 and 11). One possible reason is that the surface area of these polymer-derived catalysts is extremely low $\left(<1 \mathrm{~m}^{2} \mathrm{~g}^{-1}\right)$; they are not suitable for the liquid- phase catalytic reaction. Therefore, we then performed the gasphase isotopic $\mathrm{H}_{2}-\mathrm{D}_{2}$ exchange experiment to investigate the dissociation of $\mathrm{H}_{2}$ on $\mathrm{P}_{900}$-PCC-polymer and Fe- $\mathrm{P}_{900}-\mathrm{PCC}$ polymer. As shown in Supplementary Fig. 16a, under the continuous flow of $\mathrm{H}_{2}$ and $\mathrm{D}_{2}$, no $\mathrm{HD}(\mathrm{m} / \mathrm{z}=3)$ signal is detected over $\mathrm{P}_{900}$-PCC-polymer when the temperature is below $300{ }^{\circ} \mathrm{C}$. On the contrary, HD is formed starting at $100^{\circ} \mathrm{C}$ over $\mathrm{Fe}-$ $\mathrm{P}_{900}$-PCC-polymer, similar to the HD profile of $\mathrm{Fe}-\mathrm{P}_{900}-\mathrm{PCC}$ (Supplementary Fig. 16b), suggesting that the present P-doped and Fe-free carbon catalyst cannot activate $\mathrm{H}_{2}$, and the addition of $\mathrm{Fe}$ boosts the activation and dissociation of $\mathrm{H}_{2}$. Since above investigations have revealed that the solely Fe species was inactive for hydrogenation reaction $\left(\mathrm{Fe}-\mathrm{C}_{900}-\mathrm{PCC}\right.$ and $\mathrm{Fe} @ \mathrm{Fe}-\mathrm{C}_{900}-\mathrm{PCC}$, Table 1, entries 2, 3, and 8), so we speculated that Fe species and $\mathrm{P}$ species in $\mathrm{Fe}-\mathrm{P}_{900}-\mathrm{PCC}$ co-catalyzed the $\mathrm{H}_{2}$ dissociation and hydrogenation reaction.

Origin of catalytic activity. To probe the underlying interplay between $\mathrm{P}$ and Fe species, a series of Fe- $\mathrm{P}_{x}$-PCCs ( $x$ stands for carbonization temperature, from 700 to $1100{ }^{\circ} \mathrm{C}$ ) were synthesized by varying the carbonization temperature. The $\mathrm{P}$ contents of Fe- $\mathrm{P}_{700}-\mathrm{PCC}, \mathrm{Fe}-\mathrm{P}_{800}-\mathrm{PCC}, \mathrm{Fe}-\mathrm{P}_{900}-\mathrm{PCC}, \mathrm{Fe}-\mathrm{P}_{1000}-\mathrm{PCC}$ and $\mathrm{Fe}-$ $\mathrm{P}_{1100}-\mathrm{PCC}$ are $2.04,3.48,2.74,2.04$ and 0.91 atomic \%, respectively, determined by XPS. The state of $\mathrm{P}$ was initially investigated by analyzing $\mathrm{P} 2 \mathrm{p}$ XPS core level peaks of Fe- $\mathrm{P}_{x}$-PCCs. As shown in Fig. 2a, P 2p XPS spectrum of $\mathrm{Fe}^{-\mathrm{P}_{700}} \mathrm{PCC}$ could be deconvoluted into two bands: C-O-P $(134.4 \mathrm{eV})$ and $\mathrm{C}-\mathrm{PO}_{3} / \mathrm{C}_{2}-\mathrm{PO}_{2}$ $(133.1 \mathrm{eV})$, which are denoted as $\mathrm{PO}_{x}$, representing these $\mathrm{P}$ atoms are in a high oxidation state ${ }^{43,44}$. Remarkably, a new band in the less oxidized state appears at $132.1 \mathrm{eV}$ for $\mathrm{Fe}-\mathrm{P}_{800}-\mathrm{PCC}, \mathrm{Fe}-\mathrm{P}_{900^{-}}$ PCC, Fe- $\mathrm{P}_{1000}-\mathrm{PCC}$ and $\mathrm{Fe}-\mathrm{P}_{1100}-\mathrm{PCC}$, which are assigned to graphitic $\mathrm{P}$ group $\left(\mathrm{P}_{\text {grap }}\right)$ generated by substitution of a graphitic $\mathrm{C}$ atom in the framework of graphite with a $\mathrm{P}$ atom ${ }^{45}$. The percentages of $\mathrm{P}_{\text {grap }}$ in Fe- $\mathrm{P}_{700}-\mathrm{PCC}, \mathrm{Fe}-\mathrm{P}_{800}-\mathrm{PCC}, \mathrm{Fe}-\mathrm{P}_{900}-\mathrm{PCC}$, $\mathrm{Fe}-\mathrm{P}_{1000}-\mathrm{PCC}$ and $\mathrm{Fe}-\mathrm{P}_{1100}-\mathrm{PCC}$ are $0 \%, 6.0 \%, 15.0 \%, 17.4 \%$ and $22.7 \%$, respectively, indicating that $\mathrm{P}_{\text {grap }}$ cannot be formed at lower carbonization temperature $\left(700^{\circ} \mathrm{C}\right)$, while the higher carbonization temperature will promote more $\mathrm{P}$ atoms to insert into the skeleton of graphite forming high percentage of $\mathrm{P}_{\text {grap }}$ structure.

These results were further confirmed by solid-state ${ }^{31} \mathrm{P}$ NMR spectroscopy (Fig. 2b). ${ }^{31} \mathrm{P}$ NMR spectrum of $\mathrm{Fe}-\mathrm{P}_{700}-\mathrm{PCC}$ exhibits a broad signal at $-1.95 \mathrm{ppm}$, which is attributed to 


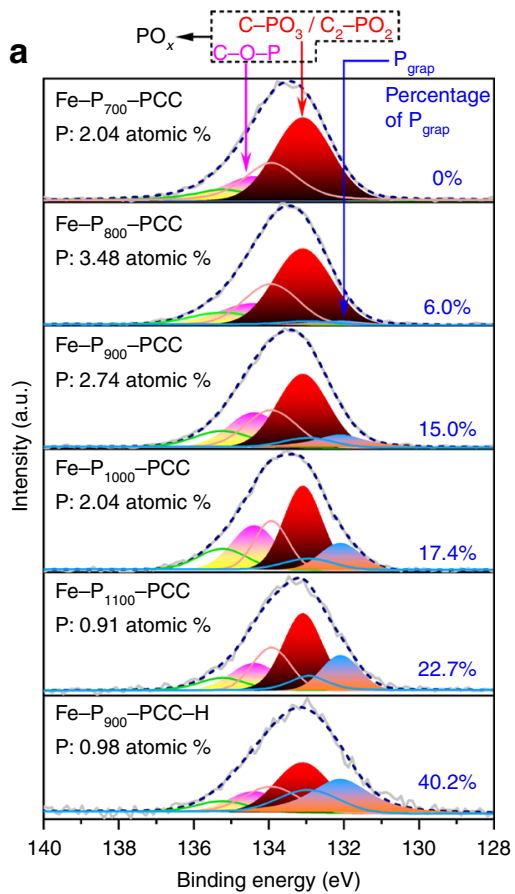

b

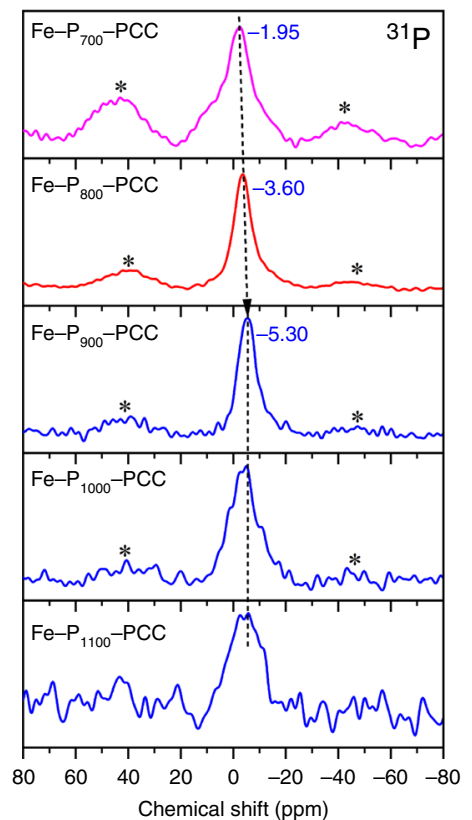

c

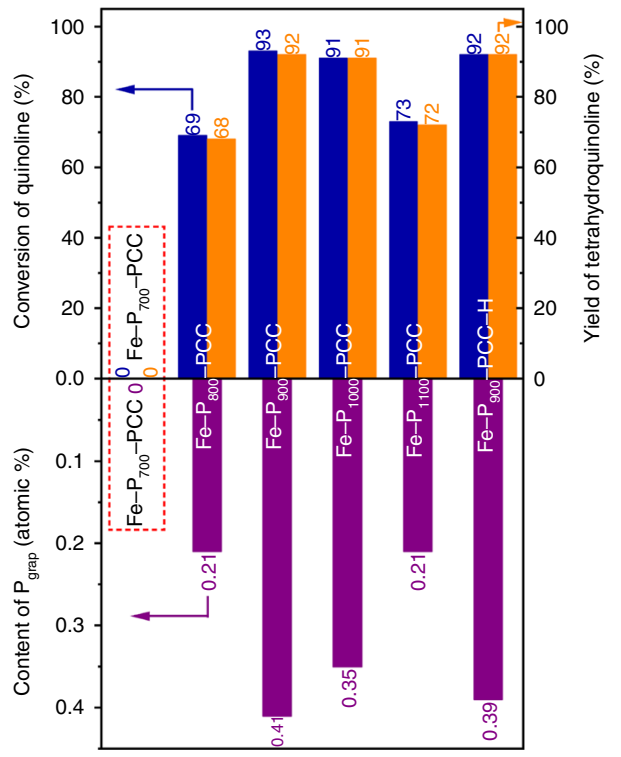

Fig. 2 Characterizations of P species. a Deconvoluted P 2p XPS spectra of Fe- $P_{x}-P C C s$. All of the spectra were deconvoluted using three doublet peaks with an area ratio of 0.5 and a separation between peaks of 0.84 eV. $\mathbf{b}$ Solid-state ${ }^{31 P}$ NMR spectra of Fe-P ${ }_{x}-P C C s$. Spinning side bands are marked with asterisk. c The relationships between catalytic activity and content of $P_{\text {grap }}$

organic phosphonate with high oxidation state ${ }^{46}$. The main peak for $\mathrm{Fe}-\mathrm{P}_{800}-\mathrm{PCC}$ shifts to $-3.60 \mathrm{ppm}$, indicating a small part of $\mathrm{P}_{\text {grap }}$ species tend to form, since the signal of $\mathrm{P}_{\text {grap }}$ is around -5 $\mathrm{ppm}^{44,47}$. For the spectra of $\mathrm{Fe}-\mathrm{P}_{900}-\mathrm{PCC}, \mathrm{Fe}-\mathrm{P}_{1000}-\mathrm{PCC}$ and $\mathrm{Fe}-$ $\mathrm{P}_{1100}$-PCC, the main peak is central at $-5.30 \mathrm{ppm}$, which shows a relatively high percentage of $\mathrm{P}_{\text {grap }}$ has formed in these catalysts. These results are in good consistence with the P $2 p$ XPS results.

To determine which type of $\mathrm{P}$ species is responsible for promoting the catalytic activity, hydrogenations of quinoline catalyzed by Fe- $\mathrm{P}_{x}$-PCCs were conducted (Fig. 2c) and it is found that their catalytic activities are positively associated with the content of $\mathrm{P}_{\text {grap }}$ (Fig. 2c, content of $\mathrm{P}_{\text {grap }}$ (atomic \%) = total content of $\mathrm{P}($ atomic $\%) \times$ percentage of $\left.\mathrm{P}_{\text {grap }}(\%)\right)$ : there is no $\mathrm{P}_{\text {grap }}$ in $\mathrm{Fe}-\mathrm{P}_{700}-\mathrm{PCC}$, and it is inactive for hydrogenation; for other four samples, the content of $\mathrm{P}_{\text {grap }}$ follows the order of $\mathrm{Fe}$ $\mathrm{P}_{900}-\mathrm{PCC}>\mathrm{Fe}-\mathrm{P}_{1000}-\mathrm{PCC}>\mathrm{Fe}-\mathrm{P}_{1100}-\mathrm{PCC}>\mathrm{Fe}-\mathrm{P}_{800}-\mathrm{PCC}$; this trend is exactly consistent with the variation tendency of the conversion of quinoline, Fe- $\mathrm{P}_{900}-\mathrm{PCC}(93 \%)>\mathrm{Fe}-\mathrm{P}_{1000}-\mathrm{PCC}$ $(91 \%)>\mathrm{Fe}-\mathrm{P}_{1100}$-PCC $(73 \%)>\mathrm{Fe}-\mathrm{P}_{800}$-PCC $(69 \%)$. In contrast, there is no correlation between the catalytic activity and the content of $\mathrm{PO}_{x}$ (listed in Supplementary Table 5). Furthermore, when $\mathrm{Fe}-\mathrm{P}_{900}-\mathrm{PCC}$ was treated with $\mathrm{H}_{2}$ at $800^{\circ} \mathrm{C}$ for $2 \mathrm{~h}$ (named as $\left.\mathrm{Fe}-\mathrm{P}_{900}-\mathrm{PCC}-\mathrm{H}\right)$, the total $\mathrm{P}$ content decreases from 2.74 atomic $\%$ in $\mathrm{Fe}-\mathrm{P}_{900}-\mathrm{PCC}$ to 0.98 atomic \% in Fe- $\mathrm{P}_{900}-\mathrm{PCC}-\mathrm{H}$, mainly due to the decrease of unstable $\mathrm{PO}_{x}$ species $(\mathrm{C}-\mathrm{O}-\mathrm{P}$ and $\left.\mathrm{C}-\mathrm{PO}_{3} / \mathrm{C}_{2}-\mathrm{PO}_{2}\right)$, but the content of $\mathrm{P}_{\text {grap }}$ is consistent (0.41 vs 0.39 atomic \%, Fig. 2a). Interestingly, $\mathrm{Fe}-\mathrm{P}_{900}-\mathrm{PCC}-\mathrm{H}$ shows equal catalytic activity in the hydrogenation of quinoline with that of the $\mathrm{Fe}-\mathrm{P}_{900}$-PCC (Fig. 2c). All of these findings demonstrate that $\mathrm{P}_{\text {grap }}$ plays an essential role in the hydrogenation reaction.

Next, the information of $\mathrm{Fe}$ species in Fe- $\mathrm{P}_{x}$-PCCs was investigated. The results of ICP-MS reveal that only a relatively few amounts of Fe remain in synthesized porous carbon (0.0072 $\mathrm{wt} \%)$ at lower carbonization temperature (Fe- $\left.\mathrm{P}_{700}-\mathrm{PCC}\right)$; higher carbonization temperature facilitates more $\mathrm{Fe}$ doped into the resultant PCCs: Fe-P ${ }_{800}-\mathrm{PCC}(0.035 \mathrm{wt} \%), \mathrm{Fe}-\mathrm{P}_{900}-\mathrm{PCC}(0.071 \mathrm{wt}$ $\%), \mathrm{Fe}-\mathrm{P}_{1000}$-PCC (0.11 wt $\left.\%\right)$, Fe-P 1000 -PCC (0.068 wt\%). EXAFS was used to analyze the coordination environments around $\mathrm{Fe}$ atoms in $\mathrm{Fe}-\mathrm{P}_{\mathrm{x}}$-PCCs. Figure $3 \mathrm{a}$ shows the Fourier transform curves at Fe K-edge of Fe- $\mathrm{P}_{x}$-PCCs. For Fe- $\mathrm{P}_{800}$-PCC, the first shell peak is at $1.53 \AA$, which slightly deviates from the coordination of $\mathrm{Fe}-\mathrm{O}(1.45 \AA)$ and might be a small part of $\mathrm{Fe}$ $\mathrm{P}$ coordination is formed. Besides, $\mathrm{Fe}-\mathrm{Fe}$ coordination could be clearly observed, indicating the formation of Fe aggregates. After raising the carbonization temperature to $900^{\circ} \mathrm{C}$, a shell peak at $1.63 \AA$ is detected, which is obviously distinct from $\mathrm{Fe}-\mathrm{Fe}(2.21$ $\AA$ ) and $\mathrm{Fe}-\mathrm{O}$ coordination and could be attributed to the $\mathrm{Fe}-\mathrm{P}$ coordination based on refs. ${ }^{48,49}$. Furthermore, there is no $\mathrm{Fe}-\mathrm{Fe}$ coordination peak in the $\mathrm{Fe}-\mathrm{P}_{900}-\mathrm{PCC}$, suggesting all $\mathrm{Fe}$ species on the surface are atomically dispersed. A predominant peak associated with $\mathrm{Fe}-\mathrm{P}$ and a weak intense feature attributed to $\mathrm{Fe}$ - Fe $(3.5 \AA)$ are simultaneously observed in Fe- $\mathrm{P}_{1000}$-PCC and Fe$\mathrm{P}_{1100}$-PCC, demonstrating that their surface Fe species are mainly atomically dispersed $\mathrm{Fe}$ alongside some Fe aggregates.

${ }^{57} \mathrm{Fe}$ Mössbauer spectroscopy is a powerful technique to investigate the coordination and valence state of $\mathrm{Fe}$ species in the solid state ${ }^{19,50}$. The best catalyst, Fe- $\mathrm{P}_{900}$-PCC, was studied by Mössbauer spectroscopy at room temperature. As shown in Fig. 3b, the spectrum of Fe- $\mathrm{P}_{900}-\mathrm{PCC}$ is well described by a single doublet with isomer shift (IS) value of $0.31 \mathrm{~mm} \mathrm{~s}^{-1}$ and quadrupole splitting (QS) value of $0.66 \mathrm{~mm} \mathrm{~s}^{-1}$, no sextet and singlet are detected, indicating only one type of Fe species exists in $\mathrm{Fe}-\mathrm{P}_{900}-\mathrm{PCC}$ and the absence of crystalline Fe species. This result is well consistent with the EXAFS result revealing no $\mathrm{Fe}$ nanoparticles are present on the surface of Fe- $\mathrm{P}_{900}-\mathrm{PCC}$, except for single Fe atoms. The value of IS is small and lies in the typical range of $\mathrm{Fe}^{3+}$ low-spin complexes, suggesting $\mathrm{Fe}$ exists in the form of $\mathrm{Fe}^{3+}$ in $\mathrm{Fe}-\mathrm{P}_{900}-\mathrm{PCC}^{51}$, which is also consistent with its Fe 2p XPS result (Supplementary Fig. 17). Furthermore, the values of IS and QS agree with Mössbauer parameters of organic P-ligand coordinated Fe complexes ${ }^{52,53}$, indicating atomically 

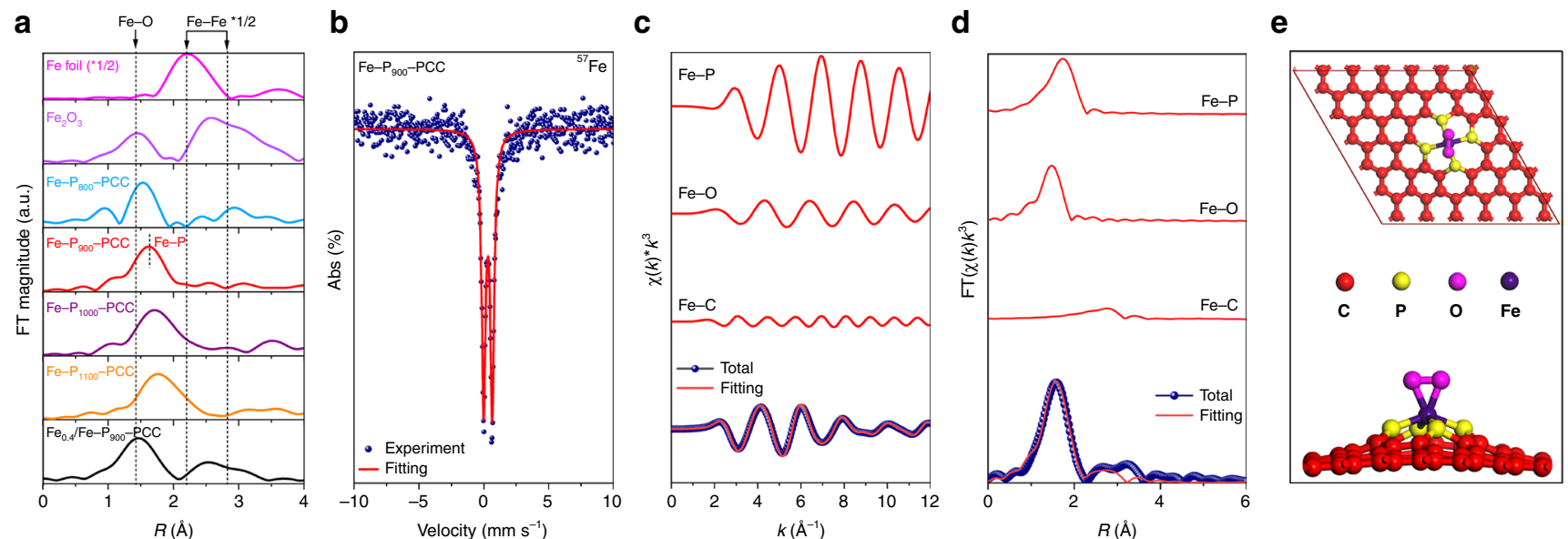

Fig. 3 Characterizations of Fe species. a EXAFS spectra of Fe- $\mathrm{P}_{x}-\mathrm{PCC}, \mathrm{Fe}_{0.4} / \mathrm{Fe}-\mathrm{P}_{900}-\mathrm{PCC}$ and reference materials $\left(\mathrm{Fe}\right.$ foil and $\left.\mathrm{Fe} \mathrm{O}_{3}\right)$. b ${ }^{57} \mathrm{Fe} \mathrm{Mössbauer}$ spectrum of Fe-P900-PCC. c, d The experimental Fe K-edge EXAFS data (blue dot) and the fitting curve (red line) of Fe-P900-PCC at $k$ and $R$ space, respectively. e Top and side views of optimized structural model of $\mathrm{O}_{2}-\mathrm{Fe}-\mathrm{P}_{4}$.

dispersed $\mathrm{Fe}$ atoms on the surface of $\mathrm{Fe}-\mathrm{P}_{900}-\mathrm{PCC}$ are coordinated by surface $\mathrm{P}_{\text {grap }}$ groups.

The coordination information of $\mathrm{Fe}$ atom in optimal $\mathrm{Fe}-\mathrm{P}_{900^{-}}$ PCC is further studied using quantitative EXAFS curve fitting (see Supplementary Table 6 for details). The best-fitting analyses are shown in Fig. 3c, d, which manifest that the Fe atoms are coordinated by four $\mathrm{P}$ atoms and a dioxygen molecule $\left(\mathrm{O}_{2}-\mathrm{Fe}-\mathrm{P}_{4}\right)$, forming a pyramidal geometry as shown in Fig. 3e; this structure is quite different from the planar structure of $\mathrm{Fe}-\mathrm{N}_{4}$. Besides, the theoretical calculations reveal that the binding energy of the $\mathrm{O}_{2^{-}}$ Fe- $\mathrm{P}_{4}$ structure is $-2.09 \mathrm{eV}$, suggesting this coordination structure is thermodynamically stable.

The formation and evolution of $\mathrm{P}$ species and Fe species in $\mathrm{Fe}-$ $\mathrm{P}_{x}$-PCC, and their relationships with catalytic activity are proposed as below. At $700^{\circ} \mathrm{C}, \mathrm{P}$ atoms cannot insert into carbon framework to form $\mathrm{P}_{\text {grap }}$; all of the $\mathrm{P}$ species are electron-deficient $\mathrm{PO}_{x}$ with high oxidation state, which cannot form stable $\mathrm{Fe}-\mathrm{P}$ structure with Fe species; the vast majority of Fe that came from raw materials were removed by hydrofluoric acid at templateremoving step, so $\mathrm{Fe}-\mathrm{P}_{700}-\mathrm{PCC}$ is inactive at all for hydrogenation; a relatively low content of $\mathrm{P}_{\text {grap }}$ is formed in $\mathrm{Fe}-\mathrm{P}_{800}$-PCC $(0.21$ atomic $\%)$, and some of $\mathrm{Fe}$ atoms are coordinated by $\mathrm{P}_{\text {grap }}$ to form $\mathrm{O}_{2}-\mathrm{Fe}-\mathrm{P}_{4}$, the conversion of quinoline raised to $69 \%$; when carbonization temperature was enhanced to $900^{\circ} \mathrm{C}$, the content of $\mathrm{P}_{\text {grap }}$ reached the maximum, and the formation of $\mathrm{Fe}$ aggregates is significantly prevented because of the coordination between $\mathrm{Fe}$ and the $\mathrm{P}_{\text {grap }}$ species, which then facilitate the construction of atomically dispersed $\mathrm{O}_{2}-\mathrm{Fe}-\mathrm{P}_{4}$ sites on the Pdoped porous carbon, and the best catalytic activity was obtained with this optimal Fe- $\mathrm{P}_{900}$-PCC catalyst; the content of $\mathrm{P}_{\text {grap }}$ decreased $(0.41-0.35,0.21$ atomic $\%$, respectively) when further increasing the carbonization temperature to 1000 and $1100^{\circ} \mathrm{C}$, and a part of $\mathrm{O}_{2}-\mathrm{Fe}-\mathrm{P}_{4}$ is aggregated to $\mathrm{Fe}$ clusters or nanoparticles, so the conversions of quinoline decreased to $91 \%$ and $73 \%$, respectively. All these investigations indicate that the $\mathrm{P}$ species have a significant impact on the evolution of Fe species; the formation of $\mathrm{P}_{\text {grap }}$ is the prerequisite for the existence of $\mathrm{O}_{2^{-}}$ $\mathrm{Fe}-\mathrm{P}_{4}$ on the surface of $\mathrm{P}$-doped porous carbon, and $\mathrm{O}_{2}-\mathrm{Fe}-\mathrm{P}_{4}$ sites are responsible for $\mathrm{H}_{2}$ dissociation and hydrogenation reaction.

In order to further prove that $\mathrm{P}_{\text {grap }}$-coordinated single-atom Fe is the active site for hydrogenation reaction, we used the reverse verification method. Chemical titration to selectively poison active sites would be quite useful to achieve this goal ${ }^{54}$; herein, we intended to convert the $\mathrm{P}_{\text {grap }}$-coordinated single $\mathrm{Fe}$ atoms to $\mathrm{Fe}$ clusters or nanoparticles via impregnating Fe species on Fe- $\mathrm{P}_{900^{-}}$ PCC. Subsequently, four $\mathrm{Fe}_{x} / \mathrm{Fe}-\mathrm{P}_{900}$-PCC ( $x$ stands for the content of impregnated $\mathrm{Fe}$, wt\%) samples with different $\mathrm{Fe}$ content $(0.11,0.20,0.40,0.95 \mathrm{wt} \%$, determined by ICP-MS) were synthesized by wet impregnation method using Fe- $\mathrm{P}_{900}$-PCC as the support. Surprisingly, the conversions of quinoline over these $\mathrm{Fe}_{x} / \mathrm{Fe}-\mathrm{P}_{900}$-PCC catalysts drastically decreased to $19 \%, 13 \%, 7 \%$, $5 \%$, respectively (Supplementary Table 7 ).

Then, the difference of surface chemical state between Fe- $\mathrm{P}_{900^{-}}$ PCC and $\mathrm{Fe}_{x} / \mathrm{Fe}-\mathrm{P}_{900}-\mathrm{PCC}$ has been investigated. The EXAFS spectra of $\mathrm{Fe}-\mathrm{P}_{900}-\mathrm{PCC}$ and $\mathrm{Fe}_{0.4} / \mathrm{Fe}-\mathrm{P}_{900}$ - $\mathrm{PCC}$ show that the original Fe-P coordination in $\mathrm{Fe}-\mathrm{P}_{900}-\mathrm{PCC}$ is replaced by $\mathrm{Fe}-\mathrm{Fe}$ and $\mathrm{Fe}-\mathrm{O}$ coordination after external $\mathrm{Fe}$ sources were impregnated on the surface of $\mathrm{Fe}-\mathrm{P}_{900}-\mathrm{PCC}$ (Fig. 3a), which suggests that

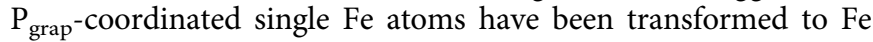
aggregates. On the other hand, the main peak of P 2p XPS spectra of $\mathrm{Fe}_{x} / \mathrm{Fe}-\mathrm{P}_{900}-\mathrm{PCC}$ has shifted to higher binding energy after introducing $\mathrm{Fe}$ species into $\mathrm{Fe}-\mathrm{P}_{900}$ - $\mathrm{PCC}$, and the shifts become more obvious with the increase of Fe loading (Supplementary Fig. 18), which suggests that the electronic state of $P$ species has been changed by the post-impregnation $\mathrm{Fe}$, and these changes of Fe species and $\mathrm{P}$ species lead to sharp decreases in catalytic activity, reversely proving that $\mathrm{P}_{\text {grap }}$-coordinated single-atom $\mathrm{Fe}$ is the active site of this Fe-P-C catalyst.

DFT calculations. To understand the possible mechanism for the hydrogenation of quinoline, we studied the reaction process with DFT calculations, which initially reveals that the bond length of $\mathrm{O}$ $-\mathrm{O}$ in $\mathrm{O}_{2}-\mathrm{Fe}-\mathrm{P}_{4}$ is $1.314 \AA$; the two oxygen atoms have a total magnetic moment of $0.77 \mu \mathrm{B}, \mathrm{O}_{2}$ gains approximately one electron from Fe- $\mathrm{P}_{4}$ upon adsorption, and the adsorbed $\mathrm{O}_{2}$ is assigned as $\mathrm{O}_{2}{ }^{-}$which can be readily reduced by $\mathrm{H}_{2}$ since the reaction $\left(\mathrm{O}_{2}-\mathrm{Fe}-\mathrm{P}_{4}+2 \mathrm{H}_{2} \rightarrow \mathrm{Fe}-\mathrm{P}_{4}+2 \mathrm{H}_{2} \mathrm{O}\right)$ is exothermic by $4.08 \mathrm{eV}$. Therefore, the Fe- $\mathrm{P}_{4}$ was used as the starting point to calculate the reaction pathway of hydrogenation of quinoline. As shown in Fig. 4, the $\mathrm{H}_{2}$ preferentially adsorbs on Fe atom, the bond length of $\mathrm{H}-\mathrm{H}$ is elongated to $0.81 \AA$ with a free energy of $-0.407 \mathrm{eV}$, indicating that the $\mathrm{H}_{2}$ can easily adsorb and bond on $\mathrm{Fe}-\mathrm{P}_{4}$. On the other hand, the adsorption energy of quinoline on Fe atoms is $-0.687 \mathrm{eV}$ (Supplementary Tables 8 and 9). Then, one hydrogen is transferred to $\mathrm{N}$ atom $\left(\mathrm{C}_{9} \mathrm{H}_{8} \mathrm{~N}^{*}\right)$, leaving another hydrogen bound to Fe atom (int-2 to int-3). Hydrogenation of $\mathrm{C}_{9} \mathrm{H}_{8} \mathrm{~N}^{*}$ to adsorbed $\mathrm{C}_{9} \mathrm{H}_{9} \mathrm{~N}^{*}$ proceeds with an energy barrier of $0.38 \mathrm{eV}$ and is exothermic by $-0.348 \mathrm{eV}$ (from int- 3 to int -4 ). The 


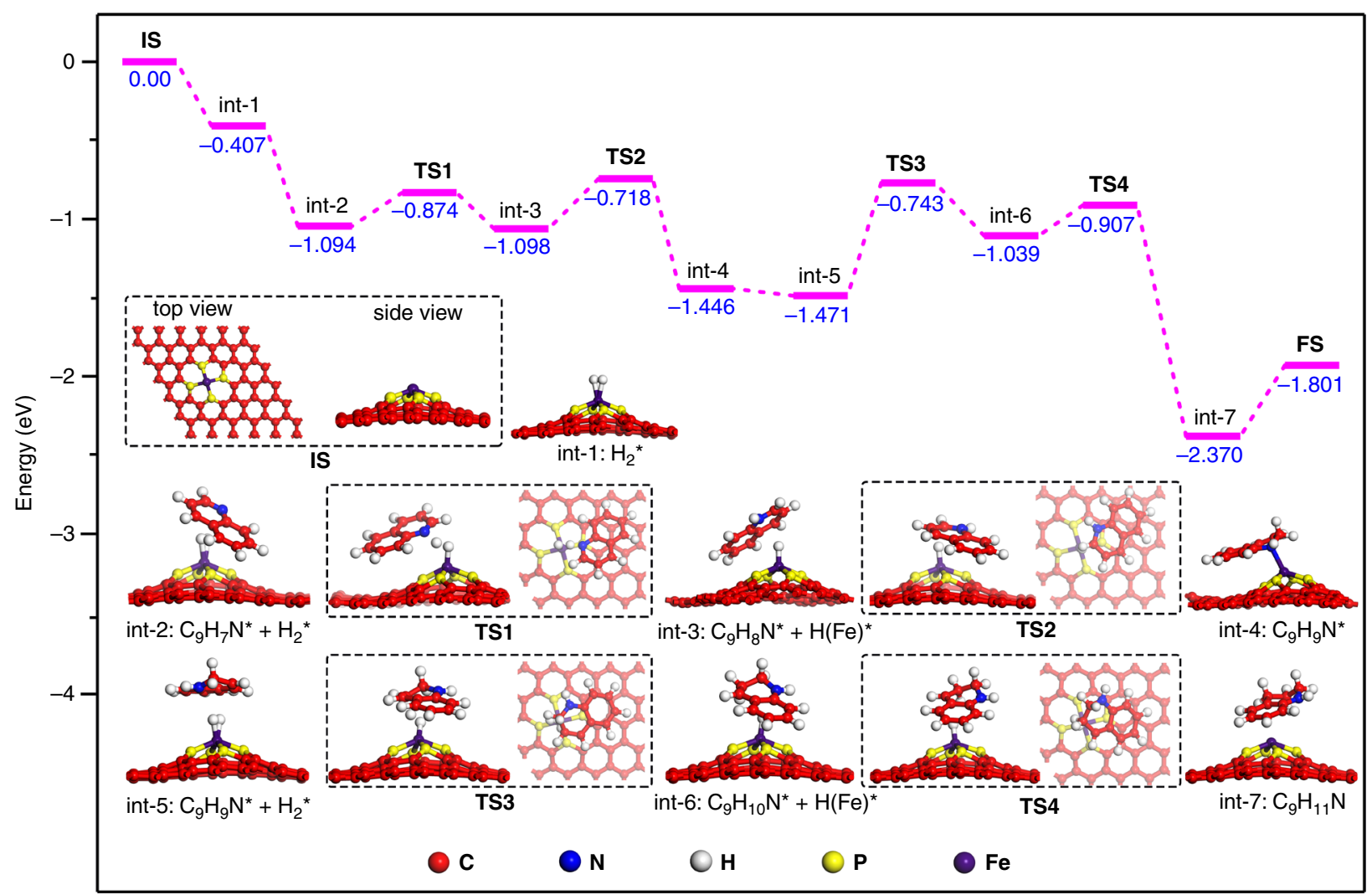

Fig. 4 Catalytic mechanism study of Fe-P $\mathbf{P}_{\mathbf{9 0 0}}-\mathbf{P C C}$ for hydrogenation of quinoline. Energies of intermediates (int) and transition states (TS) in the mechanism of quinoline stepwise hydrogenation on the $\mathrm{O}_{2}-\mathrm{Fe}_{\mathrm{P}}-\mathrm{P}_{4}$ from DFT calculations. IS initial state, $\mathrm{FS}$ final state.

reaction continues to give the final product via the addition of second hydrogen molecule, and the reaction of $\mathrm{C}_{9} \mathrm{H}_{9} \mathrm{~N}^{*}$ to $\mathrm{C}_{9} \mathrm{H}_{10} \mathrm{~N}^{*}$ (int-5 to int-6) is found to be the rate-determining step with an energy barrier of $0.728 \mathrm{eV}$.

Application of $\mathbf{F e}-\mathbf{P}_{\mathbf{9 0 0}}$-PCC. Amines are a privileged class of compounds used extensively in bulk and fine chemicals, pharmaceuticals, and materials ${ }^{55}$. Catalytic reductive amination of aldehydes and/or ketones with molecular hydrogen represents one of the most attractive methods for the preparation of advanced amines. Conventional synthesis relied on noble metalbased homogeneous or heterogeneous catalysts ${ }^{56,57}$. Very recently, $\mathrm{Co}$ or $\mathrm{Ni}$ nanoparticle catalysts encapsulated by $\mathrm{N}$ doped carbon shells derived from pyrolysis of metal organic complex have shown outstanding applications for this reaction ${ }^{58,59}$. To the best of our knowledge, the SACs have not been successfully applied in this transformation. Herein, the optimized $\mathrm{Fe}-\mathrm{P}_{900}$-PCC catalyst demonstrates excellent selectivity and activity in the synthesis of primary, secondary and tertiary amines, including some chiral amines and drug targets. As shown in Fig. 5a, a variety of alkylamines (methylamine, $n$-propylamine, $n$-hexylamine and piperidine) could react with benzaldehyde to form corresponding secondary amines $(\mathbf{5 a}-\mathbf{d})$ with excellent yields (>89\%). Moreover, ethanolamine and 2,6-dimethylaniline are also compatible with this catalytic system (5e, 5f). With methylamine as a standard amine, the as-prepared Fe- $\mathrm{P}_{900}$-PCC catalyst also showed good scope tolerance to different aldehydes and ketones, affording the desired secondary amines in 90-98\% yields $(\mathbf{5 g}-\mathbf{1})$. Gratifyingly, the original stereo configuration of the chiral amine could be perfectly retained over the $\mathrm{Fe}-\mathrm{P}_{900}-\mathrm{PCC}$ catalyst. The reductive alkylation of representative (R)-1-phenylethan-1-amine and (S)-1-phenylethan-1-amine gave the expected chiral secondary amines in $83 \%$ yield with $97 \%$ ee $(5 \mathbf{m}-\mathbf{o})$. Moreover, $\mathrm{Fe}-\mathrm{P}_{900}-\mathrm{PCC}$ catalyst also demonstrated good compatibility for the synthesis of tertiary amine, taking Buclizine (5p) as a representative target, which is a drug for the prevention and treatment of nausea, vomiting and dizziness associated with motion sickness ${ }^{60}$, could be facilely prepared in eight gram scale with $76 \%$ isolated yield via this catalytic system.

4-(aminomethyl)benzoic acid (5q) is an important hemostatic drug and a functional primary amine as well ${ }^{61}$. Currently, its industrial synthesis relies on Raney $\mathrm{Ni}$, which is still facing challenges in low selectivity and metal residues ${ }^{62}$, and a large amount of metal chelating agents (usually ethylenediaminetetraacetic acid, EDTA) and water are needed to remove $\mathrm{Ni}$ residue to parts-per-million (ppm) level. To our delight, Fe- $\mathrm{P}_{900}-\mathrm{PCC}$ catalyst showed excellent activity and selectivity in the reductive amination of 4-formylbenzoic acid (7.05 g) with aqueous ammonia in water under mild reaction temperature $\left(75^{\circ} \mathrm{C}\right)$, almost quantitative yield (98\%) of the desired $\mathbf{5 q}$ was obtained without any other products observed. ICP-MS test revealed that there is almost no metal contaminations remained in the final aqueous reaction solution ( $\mathrm{Fe}, \mathrm{Co}, \mathrm{Ni}, \mathrm{Cu}<10 \mathrm{ppb}$ ), while the $\mathrm{Ni}$ residue was detected to be as high as $28,653 \mathrm{ppb}$ when Raney $\mathrm{Ni}$ is used as the catalyst under the same reaction conditions, demonstrating the great potential of present Fe- $\mathrm{P}_{900}$-PCC in the synthesis of primary amines, particularly for medical reagent.

Functionalized anilines are important intermediates or building blocks in chemical industry ${ }^{63}$, and heterogeneous hydrogenation of nitroarenes with $\mathrm{H}_{2}$ to prepare anilines has been extensively studied by supported nanoparticle catalysts ${ }^{64,65}$ and few SACs (e.g., $\mathrm{Pt}_{1} / \mathrm{FeO}_{x} 66, \mathrm{Pt}_{1} / \alpha-\mathrm{MoC}^{67}$ ), but to date the $\mathrm{Fe}$ based SAC has not been investigated. Similarly, the main challenge for this transformation is the selective hydrogenation of functional nitroarenes bearing another moiety that can 


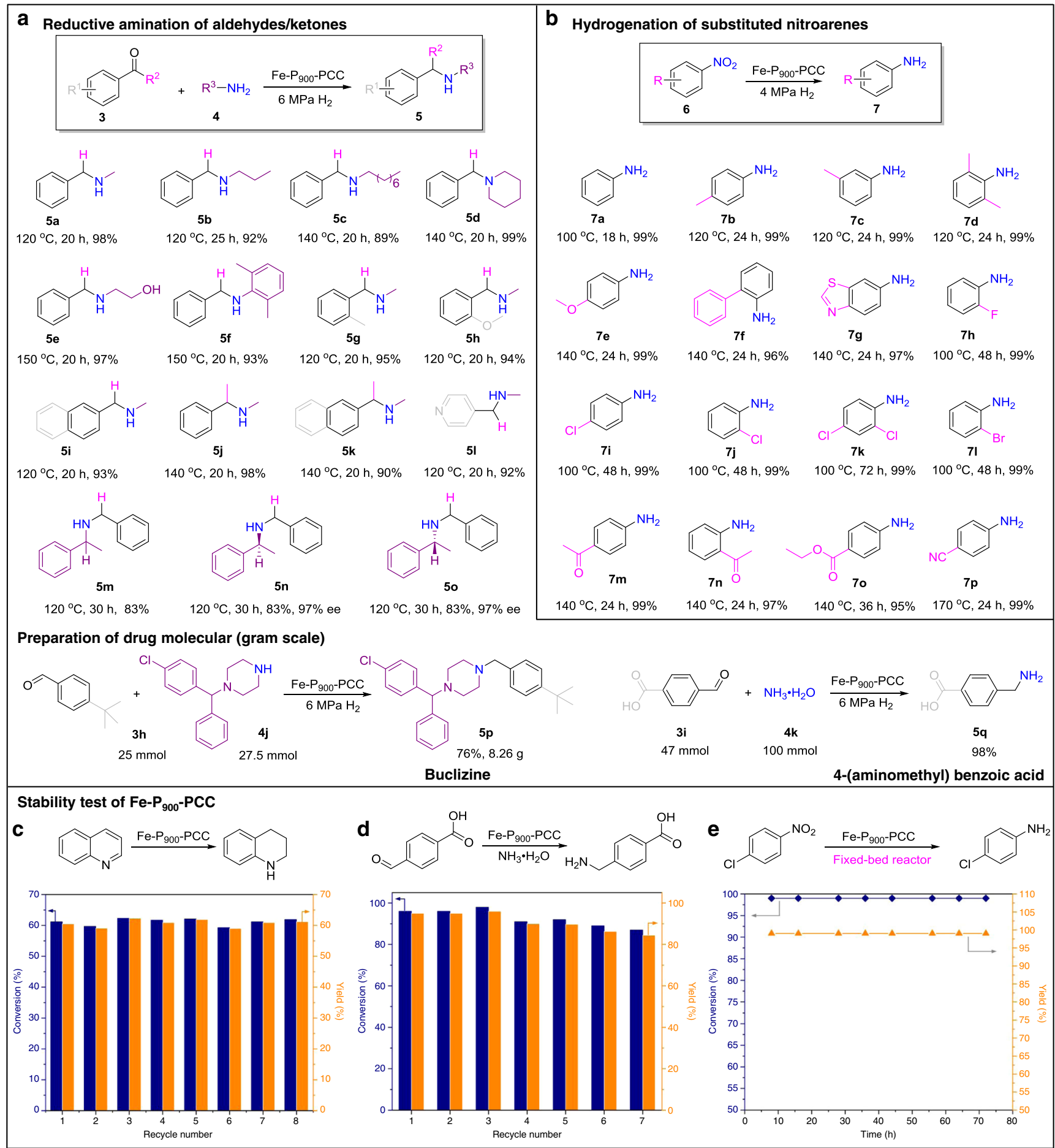

Fig. 5 Fe-P $\mathbf{P}_{\mathbf{9 0 0}}-\mathrm{PCC}$ catalyzed reductive amination and hydrogenation reactions. a Reaction conditions: $2 \mathrm{mmol}$ aldehydes/ketone, $40 \mathrm{mg}$ Fe- $\mathrm{P}_{900}-\mathrm{PCC}$, $3 \mathrm{mmol}$ amine, $5 \mathrm{~mL}$ ethanol, $6 \mathrm{MPa} \mathrm{H}_{2}$. Yields are determined by $\mathrm{GC}$ using 1,4-dioxane as an internal standard. Reaction conditions of gram scale experiments: for synthesis of $\mathbf{5 p}, 25 \mathrm{mmol} \mathbf{3} \mathbf{h}, 27.5 \mathrm{mmol} \mathbf{4 j}, 500 \mathrm{mg}$ Fe-P9o0 $-\mathrm{PCC}, 30 \mathrm{~mL}$ ethanol, $6 \mathrm{MPa} \mathrm{H}_{2}, 120^{\circ} \mathrm{C}, 30 \mathrm{~h}$, isolated yield; for synthesis of 5q, $47 \mathrm{mmol} \mathbf{3 i}, 15 \mathrm{~mL}$ aqueous ammonia $\left(100 \mathrm{mmol} \mathrm{NH} \mathrm{N}_{3}\right), 15 \mathrm{~mL} \mathrm{H} \mathrm{H}_{2} \mathrm{O}, 700 \mathrm{mg}$ Fe- $\mathrm{P}_{900}-\mathrm{PCC}, 6 \mathrm{MPa} \mathrm{H}_{2}, 75^{\circ} \mathrm{C}, 30 \mathrm{~h}$, yield is determined by high performance liquid chromatography (HPLC). b Reaction conditions: $1 \mathrm{mmol}$ substrate, $100 \mathrm{mg}$ Fe- $\mathrm{P}_{900}-\mathrm{PCC}, 4 \mathrm{MPa} \mathrm{H}_{2}, 2 \mathrm{~mL}$ toluene, yields are determined by GC ( $n$-hexadecane as an internal standard). Stability test of Fe- $\mathrm{P}_{900}-\mathrm{PCC}$. c Reaction conditions: $1 \mathrm{mmol}$ quinoline, $50 \mathrm{mg}$ Fe-P $900-P C C, 2 \mathrm{~mL}$ heptane, $4 \mathrm{MPa} \mathrm{H}_{2}, 150^{\circ} \mathrm{C}, 12 \mathrm{~h}$. Recovered catalyst is washed by ethanol, dried at $60^{\circ} \mathrm{C}$, and then submitted to the next batch of reaction. $\mathbf{d}$ Reaction conditions: $2 \mathrm{mmol}$ substrate, $2 \mathrm{~mL}$ aqueous ammonia, $40 \mathrm{mg} \mathrm{Fe}-\mathrm{P}_{900}-\mathrm{PCC}, 3 \mathrm{~mL} \mathrm{H} \mathrm{O}_{2}, 6 \mathrm{MPa} \mathrm{H}_{2}, 75^{\circ} \mathrm{C}, 2 \mathrm{Oh}$. Recovered catalyst is washed by ethanol, dried at $60{ }^{\circ} \mathrm{C}$, and then submitted to the next batch of reaction. e Long-term test of Fe-P900-PCC for hydrogenation of 4-chloronitrobenzene. Reaction conditions: $4 \mathrm{MPa}$ $\mathrm{H}_{2}, 100{ }^{\circ} \mathrm{C}, \mathrm{H}_{2}\left(50 \mathrm{~mL} \mathrm{~min}^{-1}\right)$ and $10 \mathrm{wt} \%$ 4-chloronitrobenzene in toluene $\left(0.05 \mathrm{~mL} \mathrm{~min}^{-1}\right)$ were introduced into the reactor. 
possibly be hydrogenated too ${ }^{68,69}$. As shown in Fig. 5 b, the optimized Fe- $\mathrm{P}_{900}-\mathrm{PCC}$ is not only highly active for the hydrogenation of normal nitroarenes and nitroheteroarene to yield the corresponding anilines with almost quantitative yields $(7 \mathbf{a}-\mathbf{g})$, but also highly selective for hydrogenative transformations of functional nitroarenes that possess different halogens, ketone, ester and nitrile substituents, where the side dehalogenation or undesirable hydrogenations easily occur; only nitrogroups have been selectively reduced and excellent yields (95 $-99 \%)$ of expected functional anilines $(\mathbf{7} \mathbf{h}-\mathbf{p})$ were obtained.

Stability test. The excellent catalytic performance of Fe- $\mathrm{P}_{900}-\mathrm{PCC}$ is comparable or outperformances a majority of previously reported hydrogenation catalysts (Supplementary Tables 10-12). Then, the stability of Fe- $\mathrm{P}_{900}$-PCC was first studied in the hydrogenation of quinoline in stirring autoclave; it demonstrated high stability under a controlled conversion of about $60 \%$ and could be conveniently recycled up to eight times without any deactivation (Fig. 5c). Furthermore, even under the harsh experimental conditions (aqueous ammonia solution, in the reaction of reductive amination of 4 -formylbenzoic acid), the present $\mathrm{Fe}-\mathrm{P}_{900}-\mathrm{PCC}$ displayed a just slight loss of catalytic activity within seven cycles (Fig. 5d). To investigate the generality potential of $\mathrm{Fe}-\mathrm{P}_{900}-\mathrm{PCC}$ both in different hydrogenations and reactors conditions as well, we then tested the catalyst lifetime in a fixed-bed reactor with the hydrogenation of 4chloronitrobenzene as a model reaction, as shown in Fig. 5e. Fe- $\mathrm{P}_{900}-\mathrm{PCC}$ could stably run for $72 \mathrm{~h}$ without activity loss. As revealed in the literatures that the coordination environment is crucial to the stability of the highly dispersed catalyst and $\mathrm{SAC}^{8,70}$, here the ICP-MS, XPS, EXAFS and STEM were employed to confirm the chemical stability of Fe-P ${ }_{900}$-PCC. ICPMS analysis reveals that the content of Fe in the spent Fe- $\mathrm{P}_{900^{-}}$ PCC is almost the same with the fresh catalyst $(0.069$ vs $0.071 \mathrm{wt}$ \%). P $2 p$ and $\mathrm{Fe} 2 \mathrm{p}$ XPS spectra reveal that the chemical state of $\mathrm{P}_{\text {grap }}$ and $\mathrm{Fe}$ species is constant (Supplementary Fig. 19a, b), the content of $\mathrm{P}_{\text {grap }}$ remains unchanged at 0.41 atomic\% before and after hydrogenations (Supplementary Table 5). The AC-STEM image and $\mathrm{Fe}$ K-edge EXAFS spectrum of spent $\mathrm{Fe}-\mathrm{P}_{900}$-PCC indicate that the atomically dispersed $\mathrm{Fe}$ species are well preserved after eight repetitive runs (Supplementary Fig. 19c, d).

In summary, we have facilely developed an atomically dispersed Fe-P-C catalyst (Fe- $\left.\mathrm{P}_{900}-\mathrm{PCC}\right)$. Systematic characterizations and control experiments prove that the single $\mathrm{Fe}$ atom and the surface $\mathrm{P}_{\text {grap }}$ species formed a unique distorted $\mathrm{O}_{2}-\mathrm{Fe}-\mathrm{P}_{4}$ structure on the P-doped porous carbon. After the dioxygen of $\mathrm{O}_{2}-\mathrm{Fe}-\mathrm{P}_{4}$ was reduced by $\mathrm{H}_{2}$ under reaction conditions, the insitu-generated $\mathrm{Fe}-\mathrm{P}_{4}$ sites displayed outstanding catalytic activity, selectivity and substrate generality in hydrogenations and reductive amination reactions to produce a wide variety of primary, secondary and tertiary amines, including drug targets. On the contrary, the planar Fe- $\mathrm{N}_{4}$ active site in the corresponding $\mathrm{Fe}-\mathrm{N}-\mathrm{C}$ catalyst was inactive for hydrogenations under the same reaction conditions. Moreover, the Fe- $\mathrm{P}_{900}$-PCC exhibits remarkable hydrogenation stability in the autoclave and fixed-bed reactors. Our work provides the indication of heterogeneous MP-C SACs, which will broaden the fabrication of SACs and inspire their applications in heterogeneous catalysis.

\footnotetext{
Methods

Materials. Sucrose (ultrapure, 99.9\%) was purchased from Shanghai Macklin Biochemical Co. Ltd. Cyanamide (98\%) and silica colloid (nanoparticle dispersed in water, $40 \mathrm{wt} \%$, particle size $(14 \mathrm{~nm})$, surface area $\left.\left(250 \mathrm{~m}^{2} \mathrm{~g}^{-1}\right)\right)$ were purchased from Alfa Aesar (China) Chemicals Co. Ltd and Adamas Reagent Ltd. Phytic acid solution $\left(50 \mathrm{wt} \%\right.$ in $\mathrm{H}_{2} \mathrm{O}$ ) was purchased from Aladdin Industrial Cooperation. Hydrofluoric acid (40 wt\%) was purchased from Shanghai Chemical Reagent Co. Ltd. All of the chemical reagents were used as received without further purification.
}

Ultrapure water $(18.25 \mathrm{M} \Omega \mathrm{cm})$ was obtained from the Molecular Molelement 1810 A system.

Synthesis of Fe-P9oo-PCC. Sucrose (12.5 g) and phytic acid solution (5 g) were dissolved into $50 \mathrm{~g}$ ultrapure water, followed by the addition of $20 \mathrm{~g}$ silica colloid; the mixture was stirred at room temperature for $12 \mathrm{~h}$ to obtain a homogeneous slurry. Then the mixture was placed in a drying oven at $100^{\circ} \mathrm{C}$ for $8 \mathrm{~h}$ and $160^{\circ} \mathrm{C}$ for another $8 \mathrm{~h}$. The obtained black lumps were grounded into fine powder and then transferred into a tube furnace for carbonization under the $\mathrm{Ar}$ atmosphere. The temperature was controllably ramped at a rate of $2^{\circ} \mathrm{C} \mathrm{min}-1$ to $600{ }^{\circ} \mathrm{C}$, and subsequently $5^{\circ} \mathrm{C} \mathrm{min}-1$ to $900^{\circ} \mathrm{C}$, finally maintained at $900^{\circ} \mathrm{C}$ for $3 \mathrm{~h}$. When cooling to room temperature, the obtained carbon@silica composite was treated with hydrofluoric acid $(10 \mathrm{wt} \%)$ at room temperature for $12 \mathrm{~h}$, followed by filtration and washing with ultrapure water $(1 \mathrm{~L})$; this procedure was repeated once again to completely remove the silica template. Finally, the powder was washed with ultrapure water $(3 \mathrm{~L})$ and then dried under vacuum at $100^{\circ} \mathrm{C}$ for $12 \mathrm{~h}$. Caution: after carbonization, a small amount of flammable white phosphorus will be formed on the wall of tube and off-gas pipe, which should be handled carefully. The synthetic procedures of Fe- $\mathrm{P}_{700}-\mathrm{PCC}, \mathrm{Fe}-\mathrm{P}_{800}-\mathrm{PCC}, \mathrm{Fe}-\mathrm{P}_{1000}-\mathrm{PCC}$ and $\mathrm{Fe}-$ $\mathrm{P}_{1100}$-PCC are similar to that of $\mathrm{Fe}-\mathrm{P}_{900}$-PCC, except the final carbonization temperatures were changed to $700,800,1000$ and $1100^{\circ} \mathrm{C}$, respectively.

Synthesis of $\mathbf{F e}-\mathbf{C}_{\mathbf{9 0 0}}$-PCC. $12.5 \mathrm{~g}$ sucrose was dissolved into $50 \mathrm{~g}$ ultrapure water, followed by addition of $20 \mathrm{~g}$ silica colloid, the mixture was stirred at room temperature for $12 \mathrm{~h}$ to obtain a homogeneous slurry. The procedures of drying, carbonization, and template removing were similar to that of $\mathrm{Fe}-\mathrm{P}_{900}$-PCC.

Synthesis of Fe- $\mathbf{N}_{\mathbf{9 0 0}}$-PCC. $12.5 \mathrm{~g}$ sucrose and $5 \mathrm{~g}$ cyanamide were dissolved into $50 \mathrm{~g}$ ultrapure water, followed by the addition of $20 \mathrm{~g}$ silica colloid; the mixture was stirred at room temperature for $12 \mathrm{~h}$ to obtain a homogeneous slurry. The procedures of drying, carbonization, and template removing were similar to that of $\mathrm{Fe}$ $\mathrm{P}_{900}$-PCC.

Synthesis of Fe@Fe-C $\mathbf{9 0 0}_{\mathbf{9 0 0}}$-PCC. $12.5 \mathrm{~g}$ sucrose was dissolved into $50 \mathrm{~g}$ ultrapure water; after that, $130 \mathrm{mg} \mathrm{Fe}\left(\mathrm{NO}_{3}\right)_{3} \cdot 9 \mathrm{H}_{2} \mathrm{O}$ was added and stirred for $15 \mathrm{~min}$. Followed by the addition of $20 \mathrm{~g}$ silica colloid, the mixture was stirred at room temperature for $12 \mathrm{~h}$. The procedures of drying, carbonization, and template removing were similar to that of $\mathrm{Fe}-\mathrm{P}_{900}$-PCC.

Synthesis of Fe@Fe- $\mathbf{N}_{\mathbf{9 0 0}}$-PCC. $12.5 \mathrm{~g}$ sucrose and $5 \mathrm{~g}$ cyanamide were dissolved into $50 \mathrm{~g}$ ultrapure water; after that, $130 \mathrm{mg} \mathrm{Fe}\left(\mathrm{NO}_{3}\right)_{3} \cdot 9 \mathrm{H}_{2} \mathrm{O}$ was added and stirred for $15 \mathrm{~min}$. Followed by the addition of $20 \mathrm{~g}$ silica colloid, the mixture was stirred at room temperature for $12 \mathrm{~h}$. The procedures of drying, carbonization, and template removing were similar to that of $\mathrm{Fe}-\mathrm{P}_{900}-\mathrm{PCC}$.

Synthesis of $\mathbf{F e}_{\boldsymbol{x}} / \mathbf{F e}_{\mathbf{9 0 0}}-\mathbf{P C C}$. $0.5 \mathrm{~g} \mathrm{Fe}-\mathrm{P}_{900}$-PCC was dispersed in $5 \mathrm{~mL}$ ultrapure water, and the suspension was stirred at room temperature for $15 \mathrm{~min}$. Subsequently, aqueous $\mathrm{Fe}\left(\mathrm{NO}_{3}\right)_{3}$ solution $(1 \mathrm{~mL})$ with different content of $\mathrm{Fe}$ $\left(\mathrm{NO}_{3}\right)_{3} \cdot 9 \mathrm{H}_{2} \mathrm{O}(5,10,20,40 \mathrm{mg}$, respectively) was added dropwise to the suspension. After stirring at room temperature for $12 \mathrm{~h}$, the water of suspension was evaporated at $70^{\circ} \mathrm{C}$. The obtained powder was dried under vacuum at $60{ }^{\circ} \mathrm{C}$ for $8 \mathrm{~h}$, and then calcined at $450^{\circ} \mathrm{C}$ for $2 \mathrm{~h}$ under $\mathrm{N}_{2}$. The accurate Fe loadings are $0.11,0.2$ $0.4,0.95 \mathrm{wt} \%$, respectively, determined by ICP-MS. The resultant catalysts were denoted as $\mathrm{Fe}_{0.11} / \mathrm{Fe}-\mathrm{P}_{900}$-PCC, $\mathrm{Fe}_{0.2} / \mathrm{Fe} \mathrm{P}_{900}-\mathrm{PCC}, \mathrm{Fe}_{0.4} / \mathrm{Fe}-\mathrm{P}_{900}-\mathrm{PCC}, \mathrm{Fe}_{0.95} / \mathrm{Fe}$ $\mathrm{P}_{900}-\mathrm{PCC}$.

Synthesis of Fe-P $\mathbf{P}_{\mathbf{9 0 0}}-\mathbf{P C C}-\mathbf{H} .1 \mathrm{~g}$ Fe- $\mathrm{P}_{900}-\mathrm{PCC}$ was loaded to a quartz crucible in the tube furnace and fluxed with $\mathrm{H}_{2}-\mathrm{N}_{2}$ (1:9) for $30 \mathrm{~min}$. The furnace was then heated to $800{ }^{\circ} \mathrm{C}$ in the $\mathrm{H}_{2}-\mathrm{N}_{2}$ atmosphere at a ramp of $5^{\circ} \mathrm{C} \mathrm{min}-1$ and was held at $800^{\circ} \mathrm{C}$ for $2 \mathrm{~h}$. The obtained catalyst was denoted as Fe- $\mathrm{P}_{900}-\mathrm{PCC}-\mathrm{H}$.

Synthesis of $\mathbf{P}_{\mathbf{9 0 0}}$-PCC-polymer. Polytris(4-vinylphenyl)phosphane (1 g) was placed into a tube furnace and then carbonized under the Ar atmosphere. The temperature was controllably ramped at a rate of $2{ }^{\circ} \mathrm{C} \mathrm{min}-1$ to $600{ }^{\circ} \mathrm{C}$, and subsequently $5^{\circ} \mathrm{C} \mathrm{min}-1$ to $900^{\circ} \mathrm{C}$, finally maintained at $900{ }^{\circ} \mathrm{C}$ for $3 \mathrm{~h}$. After cooling to room temperature, the obtained black powder was treated with hydrofluoric acid $(10 \mathrm{wt} \%)$ at room temperature for $12 \mathrm{~h}$; this procedure was repeated once again. After filtration, the powder was washed with ultrapure water $(3 \mathrm{~L})$ and then dried under vacuum at $100^{\circ} \mathrm{C}$ for $12 \mathrm{~h}$.

Synthesis of Fe-P $\mathbf{P}_{\mathbf{9 0 0}}-\mathbf{P C C}$-polymer. Polytris(4-vinylphenyl)phosphane (1 g) was dispersed in $10 \mathrm{~mL}$ ultrapure water. Then $25 \mathrm{mg} \mathrm{Fe}\left(\mathrm{NO}_{3}\right)_{3} \cdot 9 \mathrm{H}_{2} \mathrm{O}$ was added, the mixture was stirred at room temperature for $24 \mathrm{~h}$. After that, the water of suspension was evaporated at $70^{\circ} \mathrm{C}$, and then dried under vacuum at $60^{\circ} \mathrm{C}$ for $12 \mathrm{~h}$ The obtained material was placed into a tube furnace and carbonized under $\mathrm{Ar}$ atmosphere. The temperature was controllably ramped at a rate of $2^{\circ} \mathrm{C} \mathrm{min}^{-1}$ to $600^{\circ} \mathrm{C}$, and subsequently $5^{\circ} \mathrm{C} \mathrm{min}^{-1}$ to $900^{\circ} \mathrm{C}$, finally maintaining at $900{ }^{\circ} \mathrm{C}$ for 
$3 \mathrm{~h}$. After cooling to room temperature, the obtained black powder was treated with hydrofluoric acid (10 wt\%) at room temperature for $12 \mathrm{~h}$; this procedure was repeated once again. Finally, the powder was washed with ultrapure water $(3 \mathrm{~L})$ and then dried under vacuum at $100^{\circ} \mathrm{C}$ for $12 \mathrm{~h}$

The recommended synthesis process of Fe-P-C catalyst. Initially, the phytic acid (Aladdin Industrial Cooperation) containing Fe $(0.092 \mathrm{wt} \%)$ was used as a precursor to synthesize Fe-P-C catalyst; the Fe content of obtained Fe- $\mathrm{P}_{900}-\mathrm{PCC}$ is relatively low $(0.071 \mathrm{wt} \%)$. Then, we intended to add different amounts of Fe $\left(\mathrm{NO}_{3}\right)_{3} \cdot 9 \mathrm{H}_{2} \mathrm{O}(26,78,130,182 \mathrm{mg}$, theoretical Fe contents of the resultant Fe-P-C catalysts are $0.1,0.3,0.5,0.7 \mathrm{wt} \%$, respectively) into the initial precursors mixture of $\mathrm{Fe}-\mathrm{P}_{900}-\mathrm{PCC}$ to synthesize Fe-P-C catalysts with higher Fe content. However, the ICP-MS analyses reveal that the Fe content of obtained catalysts are $0.076,0.069$, 0.085 and $0.073 \mathrm{wt} \%$, respectively, which are close to the Fe content of Fe-P ${ }_{900}-\mathrm{PCC}$ (0.071 wt\%) but lower than the corresponding theoretical value. This is due to most of Fe species have been transformed to metallic Fe aggregates in the process of pyrolysis and then washed off by HF at the step of template removing. These results demonstrate that currently used phytic acid already contains enough amount of Fe for the synthesis of an atomically dispersed Fe-P-C catalyst and the addition of external Fe salt is not so necessary. On the other hand, considering that the phytic acid used by other researchers may have a low content of Fe, the addition of external Fe salt is recommended to guarantee the preparation of a favorable Fe-P-C catalyst.

Materials characterization. XRD patterns were collected on a Rigaku SmartLab $3 \mathrm{Kw}$ instrument using nickel-filtered $\mathrm{Cu} \mathrm{Ka}$ radiation $(40 \mathrm{kV}, 30 \mathrm{~mA})$. Raman spectra excited with a semiconductor (excitation wavelength $532 \mathrm{~nm}$ ) were collected on Labram HR 800. XPS was operated with a Thermo Scientific NEXSA Instrument. XPS samples were prepared via loading the catalysts onto an adhesive tape. The $\mathrm{N}_{2}$ adsorption/desorption isotherms were measured at $77 \mathrm{~K}$ using an ASAP 2020 Micromeritics Instrument. Before analysis, the catalysts were degassed at $180^{\circ} \mathrm{C}$ for $4 \mathrm{~h}$. Specific surface areas of catalysts were calculated from the adsorption data obtained at $P / P_{0}$ between 0.1 and 0.3 , using the BET equation. Pore size distributions were obtained from the desorption branch isotherm using the Barrett-Joyner-Halenda method. TEM and HRTEM images of catalysts were obtained with FEI Tecnai $\mathrm{G}^{2}$ F20 S-Twin electron microscope at an acceleration voltage of $200 \mathrm{kV}$. TEM samples were prepared by placing a drop of catalyst dispersion onto a holey $\mathrm{Cu}$ grid. AC-STEM images were obtained on a FEI TITAN Chemi STEM, operating at $200 \mathrm{kV}$.

The X-ray absorption spectra (XAS) including X-ray absorption near-edge structure (XANES) and extended X-ray absorption fine structure (EXAFS) of the samples were collected at Beamline 17C at the Taiwan Light Source (TLS), Beamline 44A at the Taiwan Photon Source (TPS), and BL14W1 at the Shanghai Synchrotron Radiation Facility (SSRF). All spectra were collected in ambient conditions. Data analysis was carried out with Athena and Artemis included in the Demeter package.

Solid-state ${ }^{31} \mathrm{P}$ NMR measurements were performed on a Bruker MSL 600 NMR spectrometer with a magnetic field strength of $14.1 \mathrm{~T}$. MAS rotation frequencies is $10 \mathrm{kHz}$, chemical shift referenced to $\left(\mathrm{NH}_{4}\right)_{2} \mathrm{HPO}_{4}$.

${ }^{57} \mathrm{Fe}$ Mössbauer spectrum of $\mathrm{Fe}-\mathrm{P}_{900}$ - $\mathrm{PCC}$ was collected and analyzed at the Mössbauer Effect Data Center of the Dalian Institute of Chemical Physics.

The contents of $\mathrm{Fe}$ in catalysts were measured with the Thermo Fisher ICAP RQ instrument. Process of sample treatment: $200 \mathrm{mg}$ catalyst was placed in a quartz crucible and calcined at $800^{\circ} \mathrm{C}$ for $4 \mathrm{~h}$ under the air atmosphere. After cooling to room temperature, $2 \mathrm{~mL}$ mixture acid $\left(\mathrm{HCl}: \mathrm{HNO}_{3}=3: 1\right)$ was added into the quartz crucible and soaked for $12 \mathrm{~h}$. Before running the test, the mixture was filtrated, and the filtrate was diluted by ultrapure water.

Isotopic H-D exchange experiments were performed on the Micromeritics Autochem III unit (Micromeritics Instrument) connected with an OMNI Star mass spectrometer. Two hundred milligrams catalyst was loaded in a U-shaped quartz reactor. The catalyst was first treated at $400^{\circ} \mathrm{C}$ for $1 \mathrm{~h}$ under He flow $(20 \mathrm{~mL}$ min ${ }^{-1}$ ). After cooling to room temperature, the gas flow was changed to $\mathrm{H}_{2}-\mathrm{D}_{2}$ mixture gas $\left(\mathrm{H}_{2}: 10 \mathrm{~mL} \mathrm{~min}^{-1}, \mathrm{D}_{2}: 15 \mathrm{~mL} \mathrm{~min}^{-1}\right)$ and the baseline was recorded by the mass spectrometer. After a stable baseline was obtained, the temperature of the reactor was increased from room temperature to $600^{\circ} \mathrm{C}$ with a heating rate of $3^{\circ} \mathrm{C}$ $\min ^{-1}$.

Computational methods. First-principles calculations were performed using periodic density functional (DFT) theory, as implemented in the Vienna Ab initio Simulation Package (VASP) ${ }^{71,72}$. The spin-polarized generalized gradient approximation (GGA) with the PBE functional ${ }^{73}$ was used to treat exchangecorrelation effects. A plane wave basis set with a cutoff energy of $400 \mathrm{eV}$ was selected to describe the valence electrons. The electron-ion interactions were described by the projector augmented wave $(\mathrm{PAW})^{74,75}$ method. Brillouin zone integration was performed with a $3 \times 3 \times 1$ Monkhorst-Pack ${ }^{76}(\mathrm{MP}) \mathrm{k}$-mesh and Gaussian smearing $(\sigma=0.1 \mathrm{eV})$. We used Grimme's DFT-D377 scheme to treat the van der Waals interactions semi-empirically. The self-consistent field (SCF) and force convergence criteria for structural optimization were set to $1 \times 10^{-5}$ $\mathrm{eV}$ and $0.01 \mathrm{eV} \AA^{-1}$, respectively. The climbing image nudged elastic band (CI-
$\mathrm{NEB})^{78}$ and dimer methods ${ }^{79,80}$ were used to optimize the transition state structures to achieve a force criterion of $0.03 \mathrm{eV} \AA^{-1}$. All transition states have been confirmed with the existence of one imaginary frequency whose corresponding eigenvector points in the direction of the reactant and product state Neighboring slabs were separated by at least $15 \AA$ vacuum. The adsorption energy of a gas-phase molecule is defined as $E_{\text {ads }}=E_{\text {(surface }+ \text { adsorbent) }}-E_{\text {(surface) }}$ $-E_{\text {(adsorbent) }}$

Catalytic performance examination. Substrates, catalyst, and solvent were added into a $30 \mathrm{~mL}$ high-pressure autoclave, which was flushed with pure $\mathrm{H}_{2}$ for five times before it was filled with $\mathrm{H}_{2}$ at a certain pressure. When the reaction completed, the reactor was cooled to room temperature and $\mathrm{H}_{2}$ was released. And then, internal standard and $2 \mathrm{~mL}$ solvent were added into the autoclave. After centrifugation, the reaction mixture was qualitatively analyzed by gas chromatography in combination with mass spectrometry (GC-MS, Agilent 5975C/7890A equipped with a HP-5MS column), and quantitative analysis was performed on gas chromatography with flame ionization detector (GC-FID, Agilent 6890A) with SE-54 column.

For continuous flow reaction test in fixed-bed reactor, $0.25 \mathrm{~g} \mathrm{Fe}-\mathrm{P}_{900}-\mathrm{PCC}$ and $0.25 \mathrm{~g}$ fumed $\mathrm{SiO}_{2}$ were mixed and formed to $40-100$ mesh particles; after that, the mixed catalyst was loaded into the tubular reactor. The reaction was conducted under $4 \mathrm{MPa} \mathrm{H}_{2}$ at $100{ }^{\circ} \mathrm{C} . \mathrm{H}_{2}$ and 4-chloronitrobenzene ( $10 \mathrm{wt} \%$ in toluene) were continuously introduced into the reactor at the flow rate of $50 \mathrm{~mL} \mathrm{~min}^{-1}$ and 0.05 $\mathrm{mL} \mathrm{min}^{-1}$, respectively. The conversion of 4-chloronitrobenzene and yield of 4chloroaniline were determined by GC-FID.

Recyclability test. After each reaction, the catalyst was recovered by centrifugation, and washed with ethanol $(10 \mathrm{~mL})$ for three times, dried under vacuum at $60^{\circ}$ $\mathrm{C}$ for $4 \mathrm{~h}$. The obtained catalyst was submitted to the next batch of reaction.

\section{Data availability}

All the relevant data are available from the corresponding author upon reasonable request. Source data are provided with this paper.

Received: 27 January 2020; Accepted: 22 July 2020; Published online: 13 August 2020

\section{References}

1. Tauster, S. J. Strong metal-support interactions. Acc. Chem. Res. 20, 389-394 (1987).

2. Deelen, T. W., Mejía, C. H. \& de Jong, K. P. Control of metal-support interactions in heterogeneous catalysts to enhance activity and selectivity. Nat. Catal. 2, 955-970 (2019).

3. Qiao, B. et al. Single-atom catalysis of $\mathrm{CO}$ oxidation using Pt1/FeOx. Nat. Chem. 3, 634-641 (2011).

4. Yang, X. et al. Single-atom catalysts: a new frontier in heterogeneous catalysis Acc. Chem. Res. 46, 1740-1748 (2013).

5. Cui, X., Li, W., Ryabchuk, P., Junge, K. \& Beller, M. Bridging homogeneous and heterogeneous catalysis by heterogeneous single-metal-site catalysts. Nat. Catal. 1, 385-397 (2018).

6. Li, J. et al. Highly active and stable metal single-atom catalysts achieved by strong electronic metal-support interactions. J. Am. Chem. Soc. 141, 14515-14519 (2019).

7. Zhang, J. et al. Tuning the coordination environment in single-atom catalysts to achieve highly efficient oxygen reduction reactions. J. Am. Chem. Soc. 141, 20118-20126 (2019).

8. Zhang, B. et al. Atomically dispersed Pt1-polyoxometalate catalysts: how does metal-support interaction affect stability and hydrogenation activity? J. Am. Chem. Soc. 141, 8185-8197 (2019).

9. Park, J. et al. Investigation of the support effect in atomically dispersed Pt on WO3 $-\mathrm{x}$ for utilization of $\mathrm{Pt}$ in the hydrogen evolution reaction. Angew. Chem. Int. Ed. 58, 16038-16042 (2019).

10. Shan, J., Li, M., Allard, L. F., Lee, S. \& Flytzani-Stephanopoulos, M. Mild oxidation of methane to methanol or acetic acid on supported isolated rhodium catalysts. Nature 551, 605-608 (2017).

11. Daelman, N., Capdevila-Cortada, M. \& López, N. Dynamic charge and oxidation state of $\mathrm{Pt} / \mathrm{CeO} 2$ single-atom catalysts. Nat. Mater. 18, 1215-1221 (2019).

12. Liu, P. et al. Photochemical route for synthesizing atomically dispersed palladium catalysts. Science 352, 797-800 (2016).

13. Deng, D. et al. Catalysis with two-dimensional materials and their heterostructures. Nat. Nanotechnol. 11, 218-230 (2016).

14. Pan, Y. et al. Regulating the coordination structure of single-atom Fe-NxCy catalytic sites for benzene oxidation. Nat. Commun. 10, 4290 (2019). 
15. Zitolo, A. et al. Identification of catalytic sites in cobalt-nitrogen-carbon materials for the oxygen reduction reaction. Nat. Commun. 8, 957 (2017).

16. Deng, D. et al. A single iron site confined in a graphene matrix for the catalytic oxidation of benzene at room temperature. Sci. Adv. 1, e1500462 (2015).

17. Chung, H. T. et al. Direct atomic-level insight into the active sites of a highperformance PGM-free ORR catalyst. Science 357, 479-484 (2017).

18. Liu, W. et al. A durable nickel single-atom catalyst for hydrogenation reactions and cellulose valorization under harsh conditions. Angew. Chem. Int. Ed. 57, 7071-7075 (2018).

19. Liu, W. et al. Discriminating catalytically active FeNx species of atomically dispersed Fe-N-C catalyst for selective oxidation of the C-H Bond. J. Am. Chem. Soc. 139, 10790-10798 (2017).

20. Patel, M. A. et al. P-doped porous carbon as metal free catalysts for selective aerobic oxidation with an unexpected mechanism. ACS Nano 10, 2305-2315 (2016).

21. Grim, S. Catalytic aspects of metal phosphine complexes. Organometallics 1, 1106-1107 (1982).

22. Alig, L., Fritz, M. \& Schneider, S. First-row transition metal (de)hydrogenation catalysis based on functional pincer ligands. Chem. Rev. 119, 2681-2751 (2019).

23. Weng, Z., Teo, S. \& Andy Hor, T. S. Metal unsaturation and ligand hemilability in Suzuki coupling. Acc. Chem. Res. 40, 676-684 (2007).

24. Han, F.-S. Transition-metal-catalyzed Suzuki-Miyaura cross-coupling reactions: a remarkable advance from palladium to nickel catalysts. Chem. Soc. Rev. 42, 5270-5298 (2013).

25. Ojima, I. New aspects of carbonylations catalyzed by transition metal complexes. Chem. Rev. 88, 1011-1030 (1988).

26. Dong, K. et al. Efficient palladium-catalyzed alkoxycarbonylation of bulk industrial olefins using ferrocenyl phosphine ligands. Angew. Chem. Int. Ed. 56, 5267-5271 (2017).

27. Zhang, L., Zhou, M., Wang, A. \& Zhang, T. Selective hydrogenation over supported metal catalysts: from nanoparticles to single atoms. Chem. Rev. 120, 683-733 (2019).

28. Li, Z. et al. Ionic liquids as precursors for efficient mesoporous iron-nitrogendoped oxygen reduction electrocatalysts. Angew. Chem. Int. Ed. 54, 1494-1498 (2015).

29. Bolm, C. A new iron age. Nat. Chem. 1, 420-420 (2009).

30. Ambrosi, A. et al. Chemically reduced graphene contains inherent metallic impurities present in parent natural and synthetic graphite. Proc. Natl Acad. Sci. USA 109, 12899-12904 (2012).

31. Kim, C. et al. Turning harmful deposition of metal impurities into activation of nitrogen-doped carbon catalyst toward durable electrochemical CO2 reduction. ACS Energy Lett. 4, 2343-2350 (2019).

32. Handa, S., Wang, Y., Gallou, F. \& Lipshutz, B. H. Sustainable Fe-ppm Pd nanoparticle catalysis of Suzuki-Miyaura cross-couplings in water. Science 349, 1087-1091 (2015).

33. Srinivas, G. et al. Synthesis of graphene-like nanosheets and their hydrogen adsorption capacity. Carbon 48, 630-635 (2010).

34. Ribeiro-Soares, J. et al. Structural analysis of polycrystalline graphene systems by Raman spectroscopy. Carbon 95, 646-652 (2015).

35. Sridharan, V., Suryavanshi, P. A. \& Menéndez, J. C. Advances in the chemistry of tetrahydroquinolines. Chem. Rev. 111, 7157-7259 (2011).

36. Chen, $\mathrm{Y}$. et al. Isolated single iron atoms anchored on $\mathrm{N}$-doped porous carbon as an efficient electrocatalyst for the oxygen reduction reaction. Angew. Chem. Int. Ed. 56, 6937-6941 (2017).

37. $\mathrm{Li}$, J. et al. Thermally driven structure and performance evolution of atomically dispersed FeN4 sites for oxygen reduction. Angew. Chem. Int. Ed. 58, 18971-18980 (2019).

38. Gu, J., Hsu, C.-S., Bai, L., Chen, H. M. \& Hu, X. Atomically dispersed Fe3+ sites catalyze efficient CO2 electroreduction to CO. Science 364, 1091-1094 (2019).

39. Zhang, H. et al. A graphene-supported single-atom FeN5 catalytic site for efficient electrochemical CO2 reduction. Angew. Chem. Int. Ed. 58, 14871-14876 (2019).

40. Primo, A., Neatu, F., Florea, M., Parvulescu, V. \& García, H. Graphenes in the absence of metals as carbocatalysts for selective acetylene hydrogenation and alkene hydrogenation. Nat. Commun. 5, 5291 (2014).

41. Gao, R. et al. Phosphorus-doped and lattice-defective carbon as metal-like catalyst for the selective hydrogenation of nitroarenes. ChemCatChem $\mathbf{9}$, 4287-4294 (2017).

42. Sun, Q. et al. Porous organic ligands (POLs) for synthesizing highly efficient heterogeneous catalysts. Chem. Commun. 50, 11844-11847 (2014).

43. Hasegawa, G. et al. High-level doping of nitrogen, phosphorus, and sulfur into activated carbon monoliths and their electrochemical capacitances. Chem. Mater. 27, 4703-4712 (2015)

44. Albero, J. et al. Phosphorus-doped graphene as a metal-free material for thermochemical water reforming at unusually mild conditions. ACS Sustain. Chem. Eng. 7, 838-846 (2019).
45. Rosas, J. M., Ruiz-Rosas, R., Rodríguez-Mirasol, J. \& Cordero, T. Kinetic study of the oxidation resistance of phosphorus-containing activated carbons. Carbon 50, 1523-1537 (2012).

46. Puziy, A. M., Poddubnaya, O. I., Socha, R. P., Gurgul, J. \& Wisniewski, M. XPS and NMR studies of phosphoric acid activated carbons. Carbon 46, 2113-2123 (2008).

47. Shin, J., Bertoia, J., Czerwinski, K. R. \& Bae, C. A new homogeneous polyme support based on syndiotactic polystyrene and its application in palladiumcatalyzed Suzuki-Miyaura cross-coupling reactions. Green Chem. 11, 1576-1580 (2009)

48. Chung, D. Y. et al. Large-scale synthesis of carbon-shell-coated FeP nanoparticles for robust hydrogen evolution reaction electrocatalyst. J. Am. Chem. Soc. 139, 6669-6674 (2017).

49. Cho, G. et al. Transition metal-doped FeP nanoparticles for hydrogen evolution reaction catalysis. Appl. Surf. Sci. 510, 145427-145433 (2020).

50. Zhu, Y., Zhang, B., Liu, X., Wang, D. \& Su, D. Unravelling the structure of electrocatalytically active Fe-N complexes in carbon for the oxygen reduction reaction. Angew. Chem. Int. Ed. 53, 10673-10677 (2014).

51. Silver, J. \& Withnall, R. Probes of structural and electronic environments of phosphor activators: Mössbauer and Raman spectroscopy. Chem. Rev. 104, 2833-2856 (2004).

52. Daifuku, S. L., Kneebone, J. L., Snyder, B. E. R. \& Neidig, M. L. Iron(II) active species in iron-bisphosphine catalyzed Kumada and Suzuki-Miyaura crosscouplings of phenyl nucleophiles and secondary alkyl halides. J. Am. Chem. Soc. 137, 11432-11444 (2015).

53. Daifuku, S. L., Al-Afyouni, M. H., Snyder, B. E. R., Kneebone, J. L. \& Neidig, M. L. A combined Mössbauer, magnetic circular dichroism, and density functional theory approach for iron cross-coupling catalysis: electronic structure, in situ formation, and reactivity of iron-mesityl-bisphosphines. $J$. Am. Chem. Soc. 136, 9132-9143 (2014).

54. Qi, W. et al. Oxidative dehydrogenation on nanocarbon: identification and quantification of active sites by chemical titration. Angew. Chem. Int. Ed. 52, 14224-14228 (2013).

55. Fu, M., Shang, R., Cheng, W.-M. \& Fu, Y. Boron-catalyzed Nalkylation of amines using carboxylic acids. Angew. Chem. Int. Ed. 54, 9042-9046 (2015)

56. Senthamarai, T. et al. Simple ruthenium-catalyzed reductive amination enables the synthesis of a broad range of primary amines. Nat. Commun. 9 , 4123 (2018)

57. Liang, G. et al. Production of primary amines by reductive amination of biomass-derived aldehydes/ketones. Angew. Chem. Int. Ed. 56, 3050-3054 (2017).

58. Jagadeesh, R. V. et al. MOF-derived cobalt nanoparticles catalyze a general synthesis of amines. Science 358, 326-332 (2017).

59. Hahn, G., Kunnas, P., de Jonge, N. \& Kempe, R. General synthesis of primary amines via reductive amination employing a reusable nickel catalyst. Nat. Catal. 2, 71-77 (2019).

60. Mostafa, G. A. E. \& Al-Badr, A. A. Chapter 1-Buclizine. Profiles Drug Substances, Excip. Relat. Methodol. 36, 1-33 (2011).

61. Stein, P., Rothe, E. \& Drawert, J. Use of para-aminomethylbenzoic acid (PAMBA) for preservation of concentrates of human leukocytes. Acta Biol. Med. Ger. 40, 1077-1079 (1981).

62. Gomez, S., Peters, J. A. \& Maschmeyer, T. The reductive amination of aldehydes and ketones and the hydrogenation of nitriles: mechanistic aspects and selectivity control. Adv. Synth. Catal. 344, 1037-1057 (2002).

63. Downing, R. S., Kunkeler, P. J. \& van Bekkum, H. Catalytic syntheses of aromatic amines. Catal. Today 37, 121-136 (1997).

64. Schwob, T. \& Kempe, R. A reusable Co catalyst for the selective hydrogenation of functionalized nitroarenes and the direct synthesis of imines and benzimidazoles from nitroarenes and aldehydes. Angew. Chem. Int. Ed. 55, 15175-15179 (2016).

65. Westerhaus, F. A. et al. Heterogenized cobalt oxide catalysts for nitroarene reduction by pyrolysis of molecularly defined complexes. Nat. Chem. $\mathbf{5}$, 537-543 (2013)

66. Wei, H. et al. FeOx-supported platinum single-atom and pseudo-single-atom catalysts for chemoselective hydrogenation of functionalized nitroarenes. Nat. Commun. 5, 5634 (2014).

67. Lin, L. et al. A highly CO-tolerant atomically dispersed Pt catalyst for chemoselective hydrogenation. Nat. Nanotechnol. 14, 354-361 (2019).

68. Corma, A. \& Serna, P. Chemoselective hydrogenation of nitro compounds with supported gold catalysts. Science 313, 332-334 (2006).

69. Jagadeesh, R. V. et al. Nanoscale Fe2O3-based catalysts for selective hydrogenation of nitroarenes to anilines. Science 342, 1073-1076 (2013).

70. Liu, P., Qin, R., Fu, G. \& Zheng, N. Surface coordination chemistry of metal nanomaterials. J. Am. Chem. Soc. 139, 2122-2131 (2017).

71. Kresse, G. \& Furthmuller, J. Efficient iterative schemes for ab initio totalenergy calculations using a plane-wave basis set. Phys. Rev. B 54, 11169-11186 (1996). 
72. Kresse, G. \& Furthmuller, J. Efficiency of ab-initio total energy calculations for metals and semiconductors using a plane-wave basis set. Comput. Mater. Sci. 6, 15-50 (1996).

73. Perdew, J. P., Burke, K. \& Ernzerhof, M. Generalized gradient approximation made simple. Phys. Rev. Lett. 77, 3865-3868 (1996).

74. Blöchl, P. E. Projector augmented-wave method. Phys. Rev. B 50, 17953-17979 (1994).

75. Kresse, G. \& Joubert, D. From ultrasoft pseudopotentials to the projector augmented-wave method. Phys. Rev. B 59, 1758-1775 (1999).

76. Monkhorst, H. J. \& Pack, J. D. Special points for brillouin-zone integrations. Phys. Rev. B 13, 5188-5192 (1976).

77. Grimme, S., Antony, J., Ehrlich, S. \& Krieg, H. A consistent and accurate ab initio parametrization of density functional dispersion correction (DFT-D) for the 94 elements H-Pu. J. Chem. Phys. 132, 154104-154123 (2010).

78. Henkelman, G., Uberuaga, B. P. \& Jonsson, H. A climbing image nudged elastic band method for finding saddle points and minimum energy paths. $J$. Chem. Phys. 113, 9901-9904 (2000).

79. Henkelman, G. \& Jonsson, H. A dimer method for finding saddle points on high dimensional potential surfaces using only first derivatives. J. Chem. Phys. 111, 7010-7022 (1999).

80. Heyden, A., Bell, A. \& Keil, F. Efficient methods for finding transition states in chemical reactions: comparison of improved dimer method and partitioned rational function optimization method. J. Chem. Phys. 123, 224101-224115 (2005).

\section{Acknowledgements}

This work was funded by the National Key R\&D Program of China (2018YFB1501600), the Natural Science Foundation of China (21972151, 21773271, and 21802149), the Light of West China of the Chinese Academy of Sciences (CAS), the DNL Cooperation Fund of CAS (DNL180303), and the Key Research Program of Frontier Science of CAS (QYZDJSSW-SLH051). We thank Dr. Y. Xi for the help on mechanism study. The ${ }^{57} \mathrm{Fe}$ Mössbauer spectrum was collected and analyzed at Mössbauer Effect Data Center of the Dalian Institute of Chemical Physics. We also thank beamline 17C at the Taiwan Light Source (TLS), beamline 44A at the Taiwan Photon Source (TPS) and beamline BL14W1 at the Shanghai Synchrotron Radiation Facility (SSRF).

\section{Author contributions}

X.L. and G.G. conducted the experiments, analyzed the results and wrote the manuscript. F.L. designed the research, supervised the project, and edited the manuscript. Z.L., P.S. and J.W. participated in writing the manuscript. B.Z. performed the AC-STEM char acterizations. J.Z. and Z.J. performed the XAS experiments and conducted the calculations.

\section{Competing interests}

The authors declare no competing interests.

\section{Additional information}

Supplementary information is available for this paper at https://doi.org/10.1038/s41467020-17903-0.

Correspondence and requests for materials should be addressed to F.L.

Peer review information Nature Communications thanks Huixin He and the other, anonymous, reviewer(s) for their contribution to the peer review of this work. Peer reviewer reports are available.

Reprints and permission information is available at http://www.nature.com/reprints

Publisher's note Springer Nature remains neutral with regard to jurisdictional claims in published maps and institutional affiliations.

(c) (i) Open Access This article is licensed under a Creative Commons Attribution 4.0 International License, which permits use, sharing, adaptation, distribution and reproduction in any medium or format, as long as you give appropriate credit to the original author(s) and the source, provide a link to the Creative Commons license, and indicate if changes were made. The images or other third party material in this article are included in the article's Creative Commons license, unless indicated otherwise in a credit line to the material. If material is not included in the article's Creative Commons license and your intended use is not permitted by statutory regulation or exceeds the permitted use, you will need to obtain permission directly from the copyright holder. To view a copy of this license, visit http://creativecommons.org/ licenses/by/4.0/.

(C) The Author(s) 2020 